Review

\title{
Decoding the Pluripotency Network: The Emergence of New Transcription Factors
}

\section{Kai Chuen Lee ${ }^{1}$, Wing Ki Wong ${ }^{1}$ and Bo Feng ${ }^{1,2, *}$}

1 Key Laboratory for Regenerative Medicine, Ministry of Education, School of Biomedical Sciences, Faculty of Medicine, the Chinese University of Hong Kong, Room 105A, 1/F, Lo Kwee-Seong Integrated Biomedical Sciences Building, Area 39, Shatin, N.T., Hong Kong, China; E-Mails: bolkcad@gmail.com (K.C.L.); winisama@gmail.com (W.K.W.)

2 SBS Core Laboratory, Shenzhen Research Institute, the Chinese University of Hong Kong, 4/F CUHK Shenzhen Research Institute Building, No.10, 2nd Yuexing Road, Nanshan District, Shenzhen 518057, China

* Author to whom correspondence should be addressed; E-Mail: fengbo@cuhk.edu.hk; Tel.: +852-3943-1455; Fax: +852-2603-5123.

Received: 23 October 2013; in revised form: 10 December 2013 / Accepted: 11 December 2013 / Published: 16 December 2013

\begin{abstract}
Since the successful isolation of mouse and human embryonic stem cells (ESCs) in the past decades, massive investigations have been conducted to dissect the pluripotency network that governs the ability of these cells to differentiate into all cell types. Beside the core Oct4-Sox2-Nanog circuitry, accumulating regulators, including transcription factors, epigenetic modifiers, microRNA and signaling molecules have also been found to play important roles in preserving pluripotency. Among the various regulations that orchestrate the cellular pluripotency program, transcriptional regulation is situated in the central position and appears to be dominant over other regulatory controls. In this review, we would like to summarize the recent advancements in the accumulating findings of new transcription factors that play a critical role in controlling both pluripotency network and ESC identity.
\end{abstract}

Keywords: pluripotency; embryonic stem cell; transcriptional network; transcription factor 


\section{Introduction}

The culturing of pluripotent embryonic stem cells (ESC) began in the 1980s, when they were established by explanting the inner cell mass (ICM) from mouse embryos at blastocyst stage [1]. The ICM serves as the origin of all somatic tissues and ultimately develop into an embryo. ESCs have inherited the same property of pluripotency from ICM [1]; thus, they can differentiate into all three germ layers (ectoderm, endoderm and mesoderm) while proliferating robustly in culture. This feature has rendered ESCs great potential in scientific research and medical treatment. During 2006-2007, Takahashi et al. reprogrammed human and mouse somatic cells into ESC-like pluripotent cells (termed induced pluripotent stem cells or iPSC), simply by direct transduction of ESC transcription factors Oct4, Sox2, Klf4, and c-Myc [2,3]. These groundbreaking studies have opened possibilities to generate patient-specific pluripotent cells for therapy. Its clinical relevance aroused great interest in stem cell research and attracted much attention to the investigation of molecular regulations underlying the fascinating property of pluripotency.

From the original setting of mouse ESC culture, scientists identified the active components leukaemia inhibitory factor (LIF) and bone morphogenic proteins (BMP), which maintain the pluripotency in ESCs through activating the Jak/Stat3 signaling pathway and inducing the inhibitors of differentiation (Id) genes, respectively [4-6]. In a later study, inhibition of protein kinases ERK1/2 and GSK $3 \beta$ using small-molecule inhibitors (termed " $2 \mathrm{i}$ ") was found to safeguard mouse ESC in a ground state of pluripotency, while abolishing the requirement of LIF and BMP [7]. Derivation of human ESCs was another milestone discovery in stem cell biology. When human ESCs were first established in 1998 [8], they were found to exhibit profound differences in morphology and proliferation rates from mouse ESCs. Moreover, human ESCs depend on fibroblast growth factor (FGF) and transforming growth factor beta (TGF $\beta$ )/Activin/Nodal signal pathways, but not LIF and BMP signaling, to maintain their self-renewal and pluripotency. Collectively, these signal requirements by mouse and human ESCs provided the basic foundation for subsequent understanding of the molecular regulations in pluripotency maintenance.

To date, massive investigations have been conducted to dissect the pluripotency network. The unique regulatory circuitry in pluripotent stem cells has been gradually unraveled with accumulating discoveries about the core and ancillary transcription factors [9,10], epigenetic modulation complexes that facilitate the maintenance of open chromatin structure [11,12], microRNAs (miRNA) that direct the mRNA degradation or disrupt the translation of pluripotency factors [13,14], as well as the large intergenic non-coding RNAs (lincRNAs) that affect a broad range of gene expressions in ESCs [15]. Among the various regulations that orchestrate the cellular pluripotency program, transcriptional regulation holds a central position and plays a dominant role. In this review, we would like to summarize the recent advancements in the understanding of transcriptional regulations related to pluripotency maintenance, with special focus on the accumulated findings concerning newly identified transcriptional factors which play critical roles in maintaining pluripotency besides the Oct4, Sox 2 and Nanog core complex. 


\section{Core Pluripotency Network}

\subsection{Oct4, Sox2 and Nanog}

Oct4 is a POU family transcription factor, which acts as a key regulator to govern pluripotency and ESC identity [16]. Its expression is exclusively restricted to early embryos at cleavage stages, ICM in blastocysts and germ cell lineage in later development [16]. Oct4-deficient embryos can develop to the blastocyst stage, but the ICM cells are not pluripotent and cannot form ESCs in culture [16]. In ESCs, the expression of Oct4 is under stringent control. Reduced expression causes ESC to differentiate into trophoectoderm, whereas enhanced expression induces differentiation to primitive endoderm lineage [17]. Sox2 is a high mobility group (HMG) domain containing transcription factor, which is also expressed in mouse embryos at cleavage stages and ICM of blastocysts [18]. Similarly to Oct4, Sox $2^{-/-}$mouse embryo showed a primary defect in ICM and cannot give rise to ESCs [18]. Direct knockdown of Sox2 in ESC causes rapid differentiation. Remarkably, Sox2 interacts directly with Oct4 to form a complex that recognizes Oct4-Sox 2 regulatory elements in downstream target gene promoters to regulate their transcription [18]. Interestingly, family members of Oct4 and Sox 2 could also interact directly and form various Oct-Sox complexes [19,20]. The tightly regulated expression of Oct and Sox genes as well as selective binding to different target sites by various Oct-Sox partnerships have been found to play critical roles in controlling the self-renewal and differentiations of ESCs [20,21].

Nanog is identified as another important pluripotency factor due to its unique expression pattern in undifferentiated cells [22,23]. Genetic deletion of Nanog caused early embryonic lethality, and ICM from $\mathrm{Nanog}^{-/-}$mouse embryos failed to give rise to ESCs [24]. Moreover, in mouse ESCs, elevated Nanog expression was found to alleviate the requirement of LIF for maintaining their self-renewal [22,23]. However, unlike Oct4 and Sox2, Nanog did not exhibit strong reprogramming capacity [2,3]; and $\mathrm{Nanog}^{-/-}$ESCs can partially self-renew and remain largely pluripotent [25]. Hence, Nanog was defined as a regulator that acts mainly in construction of pluripotent states rather than the housekeeping of pluripotency.

\subsection{Core Regulatory Circuitry for Pluripotency}

Oct4, Sox 2 and Nanog converge and form the primary, yet central, network that governs the robust pluripotent state. They regulate themselves by binding to their own promoter as well as the promoters of the other two, forming a feed-forward auto-regulatory circuitry that stabilizes the core regulatory circuitry in the entire pluripotency network [26,27]. In genome wide binding analyses through chromatin-immunoprecipitation (ChIP) coupled with gene chip array (ChIP-on-chip) or paired-end ditag sequencing (ChIP-PET), these three factors were found to co-occupy many of their target genes and exhibit a substantial overlapping of their binding maps in ESC genomes [9,10]. Further comparison with microarray profiles showed that most of these co-target genes were up-regulated in pluripotent state and down-regulated upon differentiation $[9,10]$, conferring the dominant role of these three factors in activating ESC-specific genes. In addition, Oct4, Sox 2 and Nanog were also found to occupy the promoter of silenced genes, which are mainly differentiation promoting genes involved in lineage specification $[9,10]$. This suggests that the core factors also form co-regulatory feedback loops to repress or suspend the expression of differentiation genes. 
Extended genome binding analyses on other ESC factors using ChIP coupled with high-throughput sequencing (ChIP-seq) further revealed that Oct4, Sox2 and Nanog often cooperate with other transcription factors or co-activators to modulate gene activation/repression in ESCs [28,29]. The number of transcriptional regulators binding to a promoter also dictates gene expression in ESCs. Promoters that are co-occupied by more than four transcription factors tend to be active in the pluripotent cells and silenced in differentiated cells, whereas promoters bound by a single factor tend to be inactive in ESC and induced upon differentiation [28,29]. Furthermore, genes activated by these core factors were often found to activate the expression their activators, thus forming feed-forward regulations to maintain the pluripotency [28-30].

Besides the well-studied Oct4, Sox 2 and Nanog, extensive studies have been carried out to identify new transcription factors in ESCs and examine the interrelationship between these factors and their connection to the entire pluripotency network. Below we will discuss these adjunct factors and their role in pluripotency maintenance.

\section{Nuclear Receptors and Pluripotency}

Nuclear receptors (NRs) are a large family of ligand-regulated transcriptional factors, which are involved in various functions, including homeostasis, reproduction, development and metabolism [31]. There are 48 NRs identified in human [32] and 49 identified in mouse [33]. All the NRs share conserved common structures. Their $N$-terminal region is the highly variable A/B domain that contains at least one transcriptional activation function 1 domain (AF-1) and several autonomous activation domains (AD). In addition, there is a conserved zinc finger DNA binding domain (DBD), a hinge region and the $C$-terminal ligand-binding domain (LBD) that overlaps with the second activation function 2 domain (AF-2). The AF1 is constitutively active in most cell types while the AF2 activity is ligand dependent $[34,35]$. The nuclear receptors without known ligands are usually referred as orphan nuclear receptors.

Recent studies have identified orphan nuclear receptors Esrrb, Nr5a2, Dax1 and GCNF for their involvement in pluripotency maintenance [36,37]. Since nuclear receptors in ESCs have been intensively reviewed recently [38], here we will only focus and recapitulate their function in regulating (or being regulated by) the core pluripotency factors at a molecular level.

\subsection{Esrrb}

Estrogen-related receptor (Esrr) $\alpha, \beta$ and $\gamma$ showed themselves to be close homologues to the estrogen receptor (ER) but do not respond to estrogen. Instead, they are constitutively active in regulating transcription without response to known ligands. Among them, Esrrb (Estrogen-related receptor $\beta$ ) is closely related to pluripotency maintenance. Esrrb ${ }^{-/-}$mouse embryos died at E10.5 due to placental defect [39]; when the placental defects were complemented with those of wild-type tetraploid embryos, proliferation of primordial germ cells (PGC) was found to be significantly reduced in the $E s r r b^{-/}$mutants [40]. Although these studies showed that Esrrb was not directly involved in the formation of pluripotent ICM cells in vivo, gene silencing via RNAi approaches robustly demonstrated that Esrrb is essential to the maintenance of mouse ESCs in culture [10,41,42]. Furthermore, Esrrb was found to promote reprogramming of somatic cells into pluripotent state, by replacing Klf4 and 
functioning collectively with Oct4 and Sox 2 to generate iPSCs [43]. These data established Esrrb as a crucial player for pluripotency maintenance.

Detailed investigation found that Esrrb directly interacts with Oct4, Sox2 and Nanog, providing insightful evidence on how Esrrb fits into the pluripotency transcription network in ESCs. Esrrb interacts with Oct4 protein [44], and activates Nanog expression by localizing to the Oct4-Sox2 elements as well as degenerate estrogen-related receptor DNA-binding elements in Nanog proximal promoter [44]. Esrrb also interacts directly with Nanog protein [41]. There are two Esrrb binding sites and one Nanog binding site in mouse Oct4 promoter. Both Nanog and Esrrb were found to be required to activate Oct4 expression [41]. In addition, Esrrb also cooperates with another core pluripotency factor, Sox2, to regulate gene expression. Employment of a motif-discovery tool called Fexcom identified the presence of Esrrb-Sox2-DNA ternary complex. Similar to the Oct4-Sox2 element, the Esrrb-Sox 2 element possesses a spacer of 2 to $8 \mathrm{bp}$ [45]. A recent study demonstrated that the full function of Esrrb requires the presence of its coactivator, Ncoa3 (Nuclear receptor coactivator 3). Ncoa3 interacts with Esrrb through its AF-2 portion of LBD to trigger downstream gene transcription and mediate its role in maintaining ESC [46]. Ncoa3 recruitment to target genes is Esrrb-dependent, as Ncoa3 alone could not support the self-renewal capacity of ESCs [46]. Concomitantly with Esrrb, Ncoa3 is also required for the induction of pluripotency upon reprogramming [46].

In return, Esrrb has been identified to be a direct target of Nanog [47]. Direct binding of Nanog to Esrrb promoter recruits RNA polymerase II to strengthen its expression [47]. It was found that Esrrb can replace Nanog in sustaining ESC self-renewal in the absence of LIF [47,48]; however, the maximal effect of Esrrb could only be achieved in the presence of Nanog. Furthermore, investigations found that Esrrb is also a downstream target of Tcf3 upon GSK3 inhibition. Both Tcf3 and $\beta$-catenin are required to induce Esrrb expression for maintaining ESC self-renewal [48], suggesting Esrrb is a downstream effector of WNT signaling in ESCs.

\subsection{Nr5a2}

Nr5a2 (nuclear receptor subfamily 5, group A, member 2/liver receptor homologue-1, Lrh-1) exhibits broad expression during the morula and epiblast stages of development. Its genetic ablation causes mouse embryos to die at the epiblast stage around E6.5-E7 [49]. ICM formation in the mutant embryos appeared unaffected, but exhibited a premature loss of Oct4 expression [50]. Consistently, knockout or silencing of $\mathrm{Nr} 5 \mathrm{a} 2$ in ESCs did not induce differentiation immediately, but resulted in a reduced expression of Oct4 and Nanog [50,51]. In 2010, Heng et al. discovered that Nr5a2 promoted somatic cell reprogramming and could replace Oct4 to generate iPSCs [51]. A later study by Guo et al. demonstrated that introduction of Nr5a2 could convert mouse epiblast stem cells (EpiSCs), which were derived from postimplantation embryos at E5.5, to the naïve pluripotency state similar to mouse ESCs [52]. These findings showed that $\mathrm{Nr} 5 \mathrm{a} 2$ plays an important role in framing the pluripotent state.

Molecular analysis has shown that $\mathrm{Nr} 5 \mathrm{a} 2$ regulates Oct4 expression by binding to its proximal promoter and upstream proximal enhancer [50]. A study by Kelly et al. substantiated that Nr5a2 regulates Oct4 through interacting with another orphan nuclear receptor, Dax1 [53]. Moreover, a recent study provided evidence that $\mathrm{Nr} 5 \mathrm{a} 2$ could activate Oct 4 by synergistically binding to the Oct4 promoter with retinoic acid receptor gamma $(\operatorname{RAR} \gamma)$ [54], which in turn promotes rapid and efficient 
reprogramming in combination with the Yamanaka's four factors. Heng et al. has also detected direct interaction between $\mathrm{Nr} 5 \mathrm{a} 2$ and Nanog through co-immunoprecipitation (Co-IP) [51]. Collectively, these data suggest that $\mathrm{Nr} 5 \mathrm{a} 2$ regulates Oct4 expression through interacting with other factors, such as Dax1, RAR $\gamma$ and Nanog; whereas, the relationship among these Nr5a2 binding partners still remains unclear. Besides activating Oct4, Nr5a2 was also found to regulate Nanog expression to promote ESC maintenance and somatic cell reprogramming [51]. ChIP analysis showed that Nr5a2 binds to the Nanog enhancer and regulates its expression directly [51]. Wu et al. further reported that $\mathrm{Nr} 5 \mathrm{a} 2$ activates Nanog expression by binding to the Nanog promoter and, meanwhile, recruiting histone acetyltransferase CREB binding protein (CBP) and histone arginine methyltransferase CARM1 to establish active epigenetic marks on it [55].

In support of the positive feed-forward regulatory model proposed by large scale mapping analyses in ESCs [28,29], $\mathrm{Nr} 5 \mathrm{a} 2$ is found to be a direct target of Oct4, especially the $O$-GlcNAcylated active form of Oct4 protein [56]. In addition, similar to Esrrb, Nr5a2 has also been identified as a direct target gene of $\beta$-Catenin and Tcf3 down-stream of the WNT signaling pathway [57]. Studies of the three-dimensional structures of $\mathrm{Nr} 5 \mathrm{a} 2$ and $\beta$-Catenin showed their direct protein-protein interaction and proposed a potential co-activation mechanism [58].

\subsection{Daxl}

Dax1 (Nr0b1/Ahch) is characterized as an atypical orphan nuclear receptor that lacks a prospective DNA binding domain [59]. Instead, it possesses three LXXLL domains that mediate protein-protein interaction in the $N$-terminal [60]. During early developmental stages, Daxl is expressed in the morula and the blastocyst where cells are pluripotent [61], suggesting a role of Dax1 in regulating pluripotency. Indeed, Daxl is enriched in undifferentiated ESCs and is repressed upon differentiation. Silencing of Daxl via RNAi in wild type ESC causes immediate differentiation and reduced viability [37]. Interestingly, increased Daxl level has also been reported to cause ESC differentiation [62]. This suggests that Dax1 acts as both a transcriptional coactivator and corepressor [63,64], whose expression level determines itself to be a transcriptional repressor or activator [63].

Detailed analysis showed that Dax1 cooperated with Nr5a2 or Oct4 proteins to control Oct4 transcription. Precise interaction motif between Nr5a2 and Dax 1 was resolved by the crystallography analysis of their complex, showing the interaction through PCFXXLP, a repressor motif conserved among all members of the Nr0b1 subfamily [64]. In addition, Dax1 was found to associate with Oct4 proteins through the POU-domain [62]. In both situations, Dax1 is believed to regulate Oct4 expression through modulating the activity of $\mathrm{Nr} 5 \mathrm{a} 2$ or Oct4 proteins, which bind directly to the corresponding DNA motifs in the Oct4 promoter and enhancers. Besides Nr5a2 and Oct4, Dax1 was also identified to interact with Nanog in a proteomics analysis [65], yet its functional significance has not been addressed.

On the other hand, Daxl is tightly regulated by the core pluripotency factors in combination with signaling pathways. Stat 3 and Oct4 regulated Daxl transcription through a putative binding site at $-158 \mathrm{bp}$ and $+2054 \mathrm{bp}$, which are located in Dax 1 promoter and an intronic region respectively [66]. Whereas, Esrrb and Sox 2 maintained Dax 1 expression though binding to the Esrrb-Sox2 motif in Dax 1 promoter [45]. Depletion of Sox 2 in ESCs induced down-regulation of Dax1 [67]. In addition, Nr5a2 
and Nanog were found to regulate Daxl expression through binding to its promoter at -128 site or to its first intron around +2770 site, respectively [68]. Overexpression and depletion of either Nr5a 2 or Nanog in mouse ESCs result in an alteration of Daxl expression [68]. Furthermore, Daxl expression was apparently affected by pharmacological activation of $\beta$-catenin in mouse ESCs [24,37], suggesting that, besides Esrrb and Nr5a2, Daxl could be another downstream target of the WNT signaling in ESCs.

\subsection{GCNF}

GCNF (germ cell nuclear receptor/Nr6a1) exhibits broad expression throughout embryonic development and adulthood. Genetic ablation of $G C N F$ caused embryonic lethality in mice, in which Oct4 expression was no longer restricted to the germ cell lineage. $G C N F^{-1}$ ESCs showed no defect in self-renewal [69], but exhibited deficiency in differentiation due to loss of repression on pluripotency genes, including Oct4 and Nanog [69-72]. This observation confers a role of GCNF in repressing Oct4 and Nanog expressions [73]. Interestingly, GCNF represses Oct4 expression through binding to an evolutionarily conserved DR0 element (direct repeats with a zero base pair spacing) located in its proximal promoter, which was also recognized by Nr5a2 for activating Oct4 transcription [50]. The binding of GCNF and $\mathrm{Nr} 5 \mathrm{a} 2$ to the same site suggests a reciprocal regulatory model for Oct4 expression by these two proteins, i.e., GCNF replaces Nr5a2 to bind to Oct4 promoter and repress its expression upon ESC differentiation [50]. In a later study, GCNF was also found to repress Nanog expression through binding to the same DR0 element located in its proximal promoter $[69,73]$, whereas Nr5a2 was found to activate Nanog expression by binding to its enhancer [51]. It is worth investigating if $\mathrm{Nr} 5 \mathrm{a} 2$ and GCNF regulate Nanog expression through a similar reciprocal regulatory mechanism.

Based on its important function in repressing pluripotency genes, demethylation of GCNF gene has been suggested as a marker for successful reprogramming [72]. Improper reprogramming of GCNF locus can lead to defects in subsequent differentiation. The $G C N F^{\text {off }}$ iPSCs (showing a loss of GCNF expression at 1.5 days after differentiation) behaved similarly to pluripotent cells except for the reduced capacity to differentiate into all lineages. $G C N F^{\text {off }}$ iPSCs were unable to give rise to chimeras after blastocyst injection. Re-introduction of GCNF could rescue the repression of Oct4 in GNCF ${ }^{\text {off }}$ iPSCs upon differentiation [72].

\section{Kruppel-Like (Klf) Transcription Factors}

The Klf family is a set of zinc finger transcription factors, which consist of 17 family members involved in various biological processes [74]. Common to all the family members is the presence of $C$-terminal tandem zinc finger motifs known for DNA binding [75,76]. Among all the family members, Klf2, Klf4 and Klf5 are expressed at a high level in ESCs but decrease upon differentiation [77]. Strong evidence demonstrated that these three Klfs play overlapping roles in maintaining ESC self-renewal [77], and they were exchangeable in reprogramming somatic cells into iPSCs [43,78].

Klf4 is the first Klf factor highlighted in stem cell biology since its discovery in facilitating somatic cell reprogramming [2]. Since then, its function in ESCs has been intensively investigated. First, Klf4 was found to play a pivotal role in maintaining Nanog expression. Direct binding of Klf4 to Nanog promoter has been reported in both human and mouse ESCs [77,79]. In mouse ESCs, a common 
binding motif for Klf2, Klf4 and Klf5 has been identified at the distal enhancer of Nanog [77]. Either mutation in this motif or triple knockdown of Klf2, Klf4 and Klf5 severely impeded the transcriptional activity of the Nanog enhancer. Moreover, Klf4 was found to interact directly with Oct4 and Sox2 proteins through its conserved zinc finger motif to activate Nanog expression in mouse ESCs [80]. A defective Oct4-Sox2-Klf4 complex interfered with normal self-renewal of ESCs and inhibited reprogramming [80]. Collectively, these findings indicate that Nanog is a direct target activated by Klf4, which explains Klf4's ability to retain the pluripotent state and prevent differentiation of embryoid bodies upon its ectopic expression [81,82]. Similarly, Klf4 could regulate human Nanog expression by direct binding to a conserved motif on Nanog proximal promoter [79]. Cooperation of Klf4 with Pbx1, Oct4 and Sox2 was found to exhibit synergistic activity to maintain Nanog transcription in human ESCs [79].

Another important target of Klf4 is Esrrb. ChIP assay has identified common binding regions for Klf2, Klf4 and Klf5 in the Esrrb upstream regulatory region [77]. Triple knockdown of Klf2, Klf4 and Klf5 severely impeded the expression of Esrrb [77], suggesting that Esrrb is a direct downstream target of these three Klfs. In support of this notion, Esrrb was found to replace Klf4 to reprogram mouse fibroblasts into iPSCs in the presence of Oct4 and Sox2 [43]. Interestingly, a feedback regulation was also identified, which showed that Esrrb could activate Klf4 expression by targeting its promoter [43]. However, these two processes were not equally important to pluripotency regulation. Ectopic expression of Esrrb could rescue the triple knockdown of Klf2, Klf4 and Klf5, preventing induced ESC differentiation; whereas, none of these Klfs could rescue the differentiation caused by Esrrb depletion [43].

Being a binding partner of Oct4 and Sox 2 as well as an upstream regulator of Nanog, Klf4 apparently sits in the core regulatory circuitry within the entire transcription network for maintaining pluripotency. Hence it is not surprising that Klf4 in fact cooperates with Oct4 and Sox2 to activate many other pluripotency genes [77], including Leftyl and Sox2 [83]. Consistently, genome-wide binding map analysis revealed that a large proportion of Klf4 binding targets overlapped with Oct4-Sox2-Nanog co-binding loci [29,84], which extended the target gene list of Klf4.

On the other hand, expression of Klf4 itself was found to rely on LIF/Stat3 signaling that was activated by supplementing Lif in ESC culture medium [85]. Klf4 is a direct downstream target of LIF/Stat3, and its ectopic expression in ESCs increased their resistance to differentiation upon LIF withdrawal [85]. These findings explained the requirement of LIF for ESC maintenance. Interestingly, using serum-free medium for ESC culture revealed that, although Klf2, Klf4 and Klf5 play a redundant role in ESC maintenance and iPSC generation, they actually respond differently to the LIF/Stat3 signal [86]. Both Klf4 and Klf5 were downstream targets of LIF/Stat3. They responded to LIF stimulation and activated downstream pluripotency genes, such as Nanog and Sox2, to maintain ESC self-renewal $[85,87,88]$. Klf2, however, was a direct target of Oct4, showing no obvious response to LIF [86]. In serum-free culture conditions, where LIF is dispensable, Klf2 functioned to activate Klfs downstream genes for maintaining ESC self-renewal [86]. Given their important positions in pluripotency maintenance, both Klf2 and Klf4 were able to reinstate naïve pluripotency in EpiSCs derived from post-implantation embryos [86].

Partially due to the functional redundancy among Klfs, no defect in ICM formation was observed in Klf2 and Klf4 null mouse embryos. Instead, $\mathrm{Klf4}^{-/-}$mice exhibited neonatal defects [89], whereas mouse 
embryos lacking Klf2 showed complex defects in hemodynamic responses and died approximately at E12.5-14.5 [90,91]. Targeted disruption of Klf5 revealed a defect in ICM, which led to failure of ESC derivation and early embryonic lethality around implantation stage. $\mathrm{Klf5}^{-1-}$ ESCs showed increased spontaneous differentiation, whereas overexpression of Klf5 could maintain ESC in the absence of LIF [88]. Collectively, Klf2, Klf4 and Klf5 possess unique properties besides their structural similarity and functional redundancy.

\section{Spalt-Like (Sall) Family}

Spalt-like family is a class of zinc finger proteins with four known members: Sall1-Sall4. They are evolutionarily conserved from Drosophila to human. Sall4 predominantly expressed in ICM of blastocysts [92] and germ line in adult tissues [93]. Elimination of Sall4 is embryonically lethal due to the failure of ICM formation [94] and Sall4 heterozygous mutant mice exhibited anorectal anomalies and exencephaly [95,96]. Consistently, in the human population, mutation on Sall4 gene leads to an autosomal dominant disorder termed Okihiro syndrome, which is associated with forehead malformation [96].

Mouse Sall4 encodes two isoform proteins Sall4a and Sall4b [97], in which Sall4a has eight zinc finger domains and Sall4b has only three [98]. The expression of both isoforms is specific to ESCs. Although Sall4a is expressed with a higher abundance, Sall4b is the isoform crucial to the maintenance of pluripotency in ESCs [97].

Studies have showed that Sall4 bound to the highly conserved distal enhancer upstream of mouse Oct4 promoter and modulated Oct4 expression to maintain ESC pluripotency [99]. Subsequent research suggested that Sall4 was likely functional through forming a protein complex with other core pluripotency factors. Sall4-Oct4 interaction was first unraveled by a proteomic study in mouse ESCs [100], and it was found to play a critical role in controlling Oct4 expression. In a recent study, direct protein-protein interactions of both Sall4-Oct4 and Sall4-Sox2 were demonstrated by pull-down assay in mouse ESCs [101]. Either Sall4-Oct4 or Sall4-Sox2 complex was found to assemble on Oct-Sox elements for gene activation in mouse ESCs; and Sall4-Oct4-Sox2 triple target sites were enriched in well-established pluripotency genes [101]. In addition to Sall4-Oct4-Sox2, Wu et al. reported Sall4 could physically interact with Nanog through its $N$-terminal region. Nanog and Sall4 co-occupied both Nanog and Sall4 enhancer regions in ESCs and activated the gene expression [102]. The direct interaction of Sall4 and Nanog was later confirmed by the Nanog -centered proteomics analysis [12,65] and supported by genome-wide ChIP-seq assay, showing that Sall4 and Nanog co-occupied many binding sites in ESCs [102]. Besides Oct4, Sox2 and Nanog, proteomics studies suggested that Sall4 could also associate with other transcription factors, such as Esrrb, Dax1, MTA2 (NuRD complex component) and Nac1 in mouse ESCs, and linked to TGF- $\beta$ and WNT signaling through interacting with Usp9X and Cxxc5 [100].

One study has systematically examined the effect of several important ESC transcription factors by global gene profiling analysis upon their depletion [103]. Two profiling paths were altered upon repression of these factors. One path was through the repression of either Oct4 or Sox2, and the other path was altered by the repression of either Esrrb, Sall4, Nanog or Tcfap4 [103], demonstrating Sall4 indeed belongs to an accessary, yet crucial, factor of pluripotency. In line with the intensive connection 
identified between Sall4 and the pluripotency network, a study demonstrated that ectopic expression of Sall4 could promote somatic cell reprograming [104].

Several studies explored the mechanism that mediates Sall4's function in regulating pluripotency. Evidence has suggested that Sall4 governs ESC self-renewal through transcriptional repression, possibly by interacting with different DNA methyltransferases (Dnmts) [105], binding to cell cycle regulator cyclin D1 [106], or competing with Oct4 and acting as an antagonist to Oct4-mediated activation of gene expression, such as Sall1-Sall3 [100,107].

\section{Fork Head/Winged Helix (Fox) Transcription Factors}

Fox family transcription factors possess a characteristic butterfly-like FOX domain responsible for DNA binding [108]. They are grouped into FoxA-FoxS, each of them functioning in distinct developmental processes. Here, we will discuss some of the members that are involved in pluripotency regulation.

FoxD3 (previously named Genesis) is required for maintenance of early embryonic cells. A loss of FoxD3 in mouse embryo led to embryonic lethality due to massive programmed cell death in epiblast cells. The ICM of the FoxD $3^{-/}$embryo failed to expand and it could not give rise to ESCs in culture [109]. FoxD3 is also required for the formation of trophoblast lineage. FoxD $3^{-/}$mouse embryos did not express the trophoectoderm marker $C d x 2$ and resulted in failure to generate trophoblast stem cells [110]. Similarly to that in mouse, FoxD3 expression was detected in human blastocysts and ESCs [111,112]. However, discrepancy exists, as literatures also showed the absence of FoxD3 in human ESCs [113].

Genetic deletion of FoxD3 in mouse ESCs via a conditional knockout strategy was found to cause no change in proliferation rate, but led to increased apoptosis and decreased ability to self-renew [114]. Differentiation analysis showed that FoxD3 was essential in repressing differentiation towards mesoderm and endoderm lineages for maintaining pluripotency [114]. Similarly, FoxD3 was found to be necessary for human ESC maintenance through a similar differentiation repressing mechanism [115]. At molecular level, it has been reported that FoxD3 cooperated with Oct4 to regulate Nanog expression in ESC [116]. On the other hand, FoxD3 was also a downstream target of Oct4 [117] and, like many other ESC transcription factors, FoxD3 could auto-regulate itself. High levels of FoxD3 could produce a locally inhibitory transcriptional effect at its promoter [117].

Other Fox members were also accounted for ESC maintenance. FoxH1 and FoxO1 mRNAs were detected in human ESC [118]. Loss of FoxH1 led to a wide range of developmental defects [119]. To date, FoxH1 has not been shown to regulate any target gene directly. Its function is possibly involved in modulating dynamic patterns of Nodal expression during early mouse development [120,121]. FoxO1 was found to be essential for human ESC maintenance, through occupying and activating Oct4 and Sox 2 promoter [122]. FoxO1 protein was primarily phosphorylated and negatively regulated by Akt serine/threonine protein kinase in various cellular contexts [123]. However, this is not true in human ESCs [122]. Interestingly, unlike other critical regulators in stem cell control, genetic deletion of FoxO1 did not cause early developmental defects in mice [124].

In addition to the above Fox members, an alternatively spliced form of FoxP1 was discovered to be expressed specifically in undifferentiated ESCs [125]. The ES-specific FoxP1 contains additional exon 
$18 \mathrm{~b}$ (equivalent to exon $16 \mathrm{~b}$ in mouse FoxP1). Inclusion of exon $18 \mathrm{~b}$ changed the DNA-binding preference of FoxP1 from promoting to inhibiting differentiation genes, thus favoring the maintenance of ESC and facilitating reprogramming [125]. Both ectopic expression of non-ES form FoxPl and silencing of the FoxP1-ES inhibited efficient reprogramming [125]. Complete deletion of FoxPl in mouse even disrupted the establishment of specific cell types [126] and resulted in early embryonic lethality at E14.5 [127].

\section{Zinc Finger Proteins}

\subsection{Zfp206 (Zscan10)}

Zfp206 (zinc finger protein 206) is highly expressed in both mouse and human ESCs and is down-regulated upon differentiation [118,128,129], suggesting that Zfp206 functions in maintaining pluripotency. ESCs stably overexpressing Zfp206 appeared morphologically normal and were resistant to retinoic acid-induced differentiation. In support of this observation, silencing of Zfp206 was not sufficient to induce differentiation in ESCs, but these cells were susceptible to differentiation induction [129].

Localization to the nucleus, presence of zinc finger domain and a SCAN domain in Zfp206 suggested itself as a transcriptional factor. Indeed, Zfp206 could activate the promoters of Nanog and Oct4 as well as its own promoter [129]. In addition, genome-wide ChIP-chip assay also identified Klf2, Klf4, Klf5, Zfp281 and Sall4 as the direct targets of Zfp206 [130]. The binding consensus sequence of Zfp206 has been predicted to be a perfect palindrome (GCGCATGCGC), suggesting Zfp206 might bind to DNA as a homodimer [130]. As with many other pluripotency regulators, reciprocal regulations by core transcription factors were also present in Zfp206. Oct4 and Nanog binding sites in Zfp206 promoter/intron were identified, and these sites were required for Oct4/Sox2 mediated-activation of Zfp206 [9,10,131], indicating that Zfp206 was a direct target of Oct4 and Nanog.

Zfp206 also contains a SCAN domain, which is known to be specific to vertebrates and highly conserved to mediate protein-protein interactions [132]. In line with this notion, physical interaction of Zfp206 with other pluripotency factors has also been demonstrated. Zfp206 directly interacted with Oct4 and Sox2 [130]. Zfp206 shared a significant number of targets with Oct4 and Sox2, which included genes that play an essential role in ESC (such as Oct4, Jaridl, Klf2) and in mouse development (such as Hoxb13, Meis1, and Pax6) [130]. Zfp206 has also been found to interact with other SCAN domain containing proteins such as Zscan4 and Zfp110 [133]. Zscan4 is known as a regulator of telomere extension and genomic stability in ESCs [134], while Zfp110 is involved in programmed cell death in the mouse embryonic neural retina [135]. Collectively, these results demonstrated that Zfp206 is an integral component of pluripotency network.

\section{2. $\operatorname{Rexl}(\mathrm{Zfp} 42)$}

Reduced expression 1 (Rexl, or Zfp42) encodes a protein containing four Cys-His-type zinc-fingers. Rex 1 is exclusively expressed in early embryos, including both trophectoderm and ICM, and is selectively restricted to germ cells during later development [136]. In both human and murine ESCs, expression of Rex 1 rapidly decreases upon differentiation; thus it has been widely used as a 
marker for pluripotent stem cells [136,137]. Consistent with Rexl's specific expression, several studies have demonstrated that it was a direct target of the core pluripotency genes in ESCs. There were binding sites for Oct4, Nanog, Dax1, NacI, and Klf4 in the Rexl promoter [28,138]. Nanog stimulated Rex 1 expression by directly activating the Rex 1 promoter, while Oct 4 and Sox 2 activated or repressed the Rex 1 promoter, depending on the cellular environment $[139,140]$. However, $\operatorname{RexI^{-/}}$ mice showed no defects in early development [141] and $\operatorname{Rexl}^{-/-}$ESCs could self-renew robustly and remain pluripotent $[142,143]$.

Genome wide binding site mapping showed that, unlike other pluripotency factors, which often form a feed-forward auto-regulatory loop with the core factors, Rex1 target sites were largely grouped with c-Myc binding sites, but not overlapped with those recognized by core pluripotency factors [28]. A later study found that Rex1 directly targeted and inhibited the transcription of Xist to maintain the X activation in mouse ESCs [144]. Rex1 was also implicated in establishing the epigenetic modifications required for maintaining allele-specific DNA methylation in imprinting genes, such as Peg3 and Gnas domains [145]. In addition, Rex1 was found to up-regulate cyclin B1/B2 expression, which subsequently activated cyclin B/CDK1 and induced the phosphorylation of DRP1, leading to mitochondrial fission that met the energy needs of human ESC via anaerobic pathways [146].

Collectively, these findings suggest that Rex1 may not be crucial to the maintenance of the core transcription network, but it plays auxiliary roles in maintaining other cellular features in ESCs.

\subsection{Zscan4}

Zscan4 (zinc finger and SCAN domain containing 4) is a novel gene identified in 2007 [147]. The expression of Zscan4 is restricted to late 2-cell stage embryos and ESCs [134,147-149]. Notably, there were only a small fraction (1\%-5\%) of undifferentiated ESCs expressing Zscan4 at a given time [147,148], but all ESCs had Zscan4 expressed at least once within nine cell passages [134]. Knockdown of Zscan4 had no direct effect on ESC self-renewal and pluripotency, but induced telomere shortening and subsequently culture crisis [134]. By a telomere chromosome orientation FISH (CO-FISH) assay, it was concluded that transient expression of Zscan4 promoted telomere recombination, leading to telomere elongation [134]. Zscan4 also reduced the DNA damage response and enhanced the efficiency of iPSC generation [150], generating iPSCs with higher genome stability [150].

ESCs have the capacity to maintain their high potency for many cell passages [151], however, loss of potency is still observed in long-term culture. In a recent finding, the developmental potency of ESC was found to be rapidly restored by the transient activation of Zscan4 [152]. Analysis on Zscan4-dependent genes in ESC or during reprogramming suggested that modulation of Zscan4 level did not alter the transcriptome dramatically [153]. To date, it remains unclear how pluripotency factors control the transient expression of Zscan4 and what is the molecular mechanism that mediate the function of Zscan4 in ESCs.

\subsection{Other Zinc Finger Proteins}

Besides the above zinc finger proteins, several other identified zinc finger proteins, including Zfp296, Zfp281 and Zfp143, have also been proposed to interact with the core pluripotency transcription factors. Zfp296 was shown to bind to CR4 in Oct4 distal enhancer to activate Oct4 
transcription. Addition of Zfp296 also enhanced reprogramming efficiency [154]. Zfp281 could physically interact with Oct4, Sox2, and Nanog [65,155]; and it activated Nanog expression directly through binding to a motif in close proximity with the Oct4-Sox 2 binding site in the Nanog proximal promoter [155]. Zfp143 regulated Nanog expression through physical interacting with Oct4 and modulating its binding to Nanog promoter [156]. Currently, there is still a lack of thorough investigation to further elaborate the functional role of these Zfps as well as to examine their importance in overall pluripotency establishment and maintenance.

\section{Developmental Pluripotency-Associated Genes (Dppa)}

Dppa family is a group of genes identified for their exclusive expression in cells within the pluripotent cycle throughout development, including blastomeres in embryos at cleavage stages, ICM of blastocysts, developing germ cells, and ESCs in culture [157-159]. Five Dppa genes (Dppa1-5) have been shown to be expressed exclusively in these undifferentiated cells, but their functions are poorly characterized. Since the physiological role of Dppal has not been evaluated [158], here we only summarized the current understanding on the functions of Dppa2-5 in pluripotency regulation.

Dppa2 and Dppa4 are closely linked genes encoding proteins containing a putative nuclear SAP (SAF-A/B, Acinux and PIAS) motif, which is responsible for DNA/RNA-binding and is involved in chromatin modification [157,160]. Although both Dppa2 and Dppa4 were expressed in ICM, developing germ line and ESCs, they exhibited different dynamic expressions during the development [157]. Depletion of either Dppa2 or Dppa4 by shRNA resulted in differentiation of ESCs $[42,161,162]$; whereas, knockdown Dppa2 also resulted in decreased proliferation of ESCs [161]. These findings suggested that Dppa2 and Dppa4 play essential roles in the maintenance of ESC pluripotency in vitro; however, the underlying mechanism and their connection to the core pluripotency regulatory circuitry remain unclear.

Dppa3 (Stella) is a definitive marker of the germ cell lineage, but its expression was also observed in preimplantation embryos and ESCs [163,164]. Similarly, Dppa3 encodes a protein with a SAP-like domain and a splicing factor motif-like structure, suggesting it functions in chromosomal organization or RNA processing [165]. $\mathrm{Dppa}^{-/-}$mice generated via targeted mutation were apparently normal at birth, but the adult females displayed severely reduced fertility due to a lack of maternal Stella-protein in their oocytes [165]. In ESCs, expression of Dppa3 has been reported to be heterogeneous in both mouse and human ESCs $[164,166]$. Single cell gene expression analysis showed that Dppa3 $(+)$ mouse ESCs were similar to the ICM, whereas Dppa3 (-) cells resembled the epiblast cells at a later stage [167]. The Dppa3 (+) and Dppa3 (-) states were exchangeable, but Dppa3's function in ESCs still remains obscure due to a lack of characterization on $D p p a 3^{-/-}$ESCs.

Dppa5 (or embryonic stem cell-specific gene 1, Esg1; or ESC associated transcript 2, Ecat2) encodes a KH-domain containing protein, and it is specifically expressed in early embryos, germ cells, and ESCs. Dppa $5^{-/-}$mice generated via gene targeting developed normally and fertile [168]. Dppa $5^{-/}$ ESCs demonstrated normal morphology, proliferation, and differentiation [168]. Hence, despite its specific expression, Dppa5 is dispensable for the establishment and maintenance of pluripotency. 


\section{T-box 3 (Tbx3)}

Tbx 3 is a member of the T-box family. In mice, homozygous mutations were embryonic lethal due to various developmental defects [169]. Studies have shown that Tbx3 was essential in the maintenance of mouse ESC self-renewal. Depletion of $T b x 3$ resulted in the loss of pluripotency and differentiation [42,170], while overexpression of $T b x 3$ was found to be sufficient to maintain the undifferentiated state in the absence of LIF [87], similar to that in Nanog-overexpressing cells [22,23].

In mouse ESCs, expression of Tbx3 was partially activated by PI3-kinase but inhibited by MAP-kinase [87]. Furthermore, Tbx3 promoter was directly bound by both Nanog and Tcf3, suggesting its regulation by WNT signal pathway or through GSK3 $\beta$ kinase [170]. On the other hand, Tbx3 predominantly stimulated Nanog expression, meanwhile targeting ESC factors Oct4, Sox2, Sall4, Lefty1, Lefty2 and Zfp42, as well as reprogramming factors Klf2, Klf4, Klf5, n-Myc and c-Myc [87,170]. Hence, it is not surprising that expression of $T b x 3$ during somatic cell reprogramming could improve the overall quality of iPSCs [170].

In human ESCs, Tbx3 overexpression promoted proliferation by repressing the expression of cell cycle regulators $N F \kappa B I B$ and $p 14^{A R F}$ [171]. During differentiation, Tbx3 depletion resulted in decreased neural differentiation [171]. Collectively, these findings indicated that Tbx3 plays an important role in maintaining pluripotency in ESCs.

\section{Germline Genes}

Germ stem cells derived from mouse embryonic primordial germ cells are pluripotent and highly resembling ESCs [172], suggesting a close relationship between germ cells and ESCs. Indeed, many ESC markers are known to be enriched in developing germ cells, such as the aforementioned Oct4, Dppa4, and Nr5a2 [173,174]; meanwhile, germline specific genes, such as Prdm14, L1td1 and Utf1, have been implicated in ESC maintenance. Here we will review studies in this area.

\section{1. $\operatorname{Prdm} 14$}

Prdm14, a PR domain-containing transcriptional regulator, was identified as one of the major determinants of human ESC identity in a whole-genome RNAi screen [175]. Prdm14 directly regulated the expression of Oct4 through its proximal enhancer [175]. In addition, deletion of Prdm14 in human ESCs resulted in increased expression of differentiation genes [175,176], whereas ectopic expression of Prdm 14 suppressed the expression of differentiation genes in embryoid bodies [176], suggesting that Prdm14 also acts as a transcriptional repressor in regulating pluripotency in human ESCs. Indeed, Prdm14 facilitated iPSC generation by repressing differentiation-related genes [175,177], in particular, the mesenchymal genes during the initiation stage [175]. Furthermore, its repressive role was proved to be mediated through cooperation with polycomb repressive complex 2 (PRC2) [177,178].

Interestingly, Prdm14 homologue in mouse is a determinant factor for germline formation and maintenance [179]. Depletion of Prdm14 did not cause obvious differentiation of mouse ESCs $[175,178,180]$. Instead, it is involved in ensuring naive pluripotency through repressing the FGF signaling pathway, or de novo DNA methyltransferases activities in ESCs [178,180]. 


\subsection{L1td1 (Ecat11)}

L1td1 (line-1 type transposase domain-containing protein 1, or ES cell associated transcript 11, Ecat11) encodes a RNA-binding protein that is abundantly expressed in mouse ESCs and is suppressed upon differentiation $[181,182]$. Despite this specific expression, $L 1 t d 1^{-1-}$ mice grew normally and were fertile. Moreover, L1td1 was dispensable for both proliferation and pluripotency of ESCs. More importantly, iPSCs could be established from $L 1 t d 1^{-/-}$fibroblasts [181].

Surprisingly, L1td1 has a critical function in human ESC maintenance. L1td1 co-localized and interacted with Lin28 via binding to common RNAs, and it was implicated in modulating the level of Oct4 expression [182]. Depletion of L1td1 resulted in immediate down-regulation of Oct4 and Nanog, and subsequently induced differentiation. In return, Oct4, Sox2, and Nanog proteins bound to the promoter of L1td1 and regulated its expression level [182].

\subsection{Utf1}

Utf1 (undifferentiated embryonic cell transcription factor 1) is expressed during early embryonic development in the cells of ICM and epiblasts; its expression is then rapidly restricted to primordial germ cells of developing embryos [183] and gonads in adults [183-186]. On one hand, Utf1 has been implied to maintain the proliferation rate of ESCs, and was required for proper teratoma formation [187,188]. On the other hand, Utf1 was shown to be dispensable for self-renewal, but ESCs with reduced Utf1 could not differentiate properly [188]. Promoter analysis has found that the mouse Utf1 is directly regulated by Oct4 and Sox2 [189]. Utf1 has also been implied to function in chromatin-associated transcriptional repression [188]. A recent study demonstrated that Utf1 buffered the poised states of bivalent genes through limiting PRC2 loading and histone 3 lysine-27 (H3K27) trimethylation, thus set activation thresholds for differentiation-promoting genes in ESCs [190].

\section{Conclusions}

To summarize, the key transcription factors Oct4, Sox 2 and Nanog form the core pluripotency circuitry with their cooperative autoregulation in ESCs. These core transcription factors work in combination to further activate other pluripotency-related genes through feed-forward regulatory loops, or to repress differentiation-promoting genes via feedback inhibitory regulations. Encompassing this core circuitry, ancillary transcription factors either provide feed-forward regulations to strengthen and stabilize the pluripotency network, or branch out from the regulating transcription network to exerting other cellular functions required for maintaining ESC identity (Table 1).

Accumulating knowledge about the transcriptional network in ESCs has provided a comprehensive elucidation of molecular regulations underlying pluripotency maintenance; however, challenges still remain to fully understand the unique property in ESCs. First, intensive investigation is required to elaborate on the complex regulatory roles of intrinsic/extrinsic signals and their connections to the transcriptional network in ESCs. Since the establishment of ESC, various signaling pathways have been implicated in regulating ESC identity. These include LIF, BMP, FGF and TGF $\beta /$ Activin, WNT, $\mathrm{SHH}$, retinoic acid signaling and much more. Although extensive research has been performed to analyze each pathway individually, many conclusions remain controversial and the combinatory effect 
of these signals remains unclear. In particular, the drastic difference between mouse ESCs and human ESCs has brought about a very puzzling situation, suggesting that the current understanding of signaling molecules is far from sufficient for manipulating ESC differentiation into desired cell types. Second, accumulating evidence has suggested that the pluripotent state is governed by a stringently controlled yet highly dynamic transcriptional network. Transcriptional regulations of individual components under this network are often associated with epigenetic modification and chromatin remodeling, and their activities are subjected to fine-tuning by post-transcriptional or post-translational modulations. Given the massive interactions among various types of regulators, it remains to be a challenging area of research to provide precise understanding of pluripotency regulation, despite the existence of advanced computation modeling technology. Collectively, investigation into the pluripotency regulations with more integrative analyses is required, in order for us to consolidate our understanding as well as to harness the full potential of human ESCs/iPSCs in various research and therapeutic applications.

Table 1. Connections between ancillary and core pluripotency transcription factors.

\begin{tabular}{|c|c|c|}
\hline Gene & Transcriptional interaction with core factors & Reference \\
\hline Esrrb & $\begin{array}{l}\text { Interacts with Oct } 4 \text {, Nanog, Sox } 2 \text { and Ncoa3; } \\
\text { Activate Nanog, Oct } 4 \text { and other genes; } \\
\text { Target of Nanog and Tcf3. }\end{array}$ & {$[41,44-48]$} \\
\hline$N r 5 a 2$ & $\begin{array}{l}\text { Interacts with Dax } 1 \text { and Rar } \gamma \\
\text { Activates Oct } 4 \text { and Nanog; } \\
\text { Direct target of Oct } 4, \beta \text {-Catenin and Tcf3. }\end{array}$ & $\begin{array}{l}{[50,51,53,54,} \\
56,57]\end{array}$ \\
\hline Daxl & $\begin{array}{l}\text { Interacts with Nanog, Oct } 4 \text { and Nr5a2; } \\
\text { Activate Oct } 4 \text { expression; } \\
\text { Target of Stat } 3 \text {, Oct } 4 \text {, Esrrb, Sox } 2, \mathrm{Nr} 5 \mathrm{a} 2 \text {, Nanog and } \beta \text {-catenin. }\end{array}$ & $\begin{array}{l}{[24,37,45} \\
62-66,68]\end{array}$ \\
\hline$G C N F$ & Repress Oct4 and Nanog upon differentiation. & {$[50,51,69,73]$} \\
\hline Klf4 & $\begin{array}{l}\text { Interacts with Oct } 4 \text { and Sox } 2 \text {; } \\
\text { Activate Nanog, Esrrb and other genes; } \\
\text { Downstream target of LIF/Stat3 signaling. }\end{array}$ & {$[43,77,80]$} \\
\hline Sall4 & $\begin{array}{l}\text { Interact with Nanog, Oct4, Sox2, Esrrb, Dax1, MTA2 and Nac1; } \\
\text { Activate Oct } 4 \text { expression; } \\
\text { Linked to TGF- } \beta \text { and WNT signaling through Usp9X and Cxxc5; } \\
\text { Involved in transcriptional repression, cell cycle regulation } \\
\text { (via binding to cyclin D1). }\end{array}$ & $\begin{array}{l}{[99-102,} \\
105,106]\end{array}$ \\
\hline FoxD3 & $\begin{array}{l}\text { Activate Nanog through cooperating with Oct4; } \\
\text { Target of Oct4; } \\
\text { High level of FoxD3 can inhibit itself. }\end{array}$ & {$[116,117]$} \\
\hline FoxOl & $\begin{array}{l}\text { Essential for human ESC maintenance; } \\
\text { Activate } O c t 4 \text { and Sox } 2 \text { in human ESCs. }\end{array}$ & {$[122]$} \\
\hline Zfp206 & $\begin{array}{l}\text { Interact with Oct4, Sox2, Zscan4 and Zfp110; } \\
\text { Activate Nanog and Oct4; } \\
\text { Target of Oct4 and Nanog. }\end{array}$ & $\begin{array}{l}{[9,10,} \\
129-131,133]\end{array}$ \\
\hline
\end{tabular}


Table 1. Cont.

\begin{tabular}{|c|c|c|}
\hline Gene & Transcriptional interaction with core factors & Reference \\
\hline Zfp296 & $\begin{array}{l}\text { Activate } O c t 4 \\
\text { Enhance reprogramming. }\end{array}$ & {$[154]$} \\
\hline Zfp281 & $\begin{array}{l}\text { Interact with Oct4, Sox } 2 \text { and Nanog; } \\
\text { Activate Nanog. }\end{array}$ & {$[65,155]$} \\
\hline $\operatorname{Rexl}$ & $\begin{array}{l}\text { Target of Oct4, Sox2, Nanog, Klf4, Dax1 and NacI; } \\
\text { Maintains X-activation, imprinting, cell cycle, and mitochondrial } \\
\text { fission in ESCs. }\end{array}$ & $\begin{array}{l}{[28,138,} \\
144-146]\end{array}$ \\
\hline Zscan4 & $\begin{array}{l}\text { Overexpression or knockdown Zscan4 did not alter the transcriptome } \\
\text { dramatically; } \\
\text { Transient expression of Zscan } 4 \text { lead to telomere elongation and can } \\
\text { restore the developmental potency of ESC. }\end{array}$ & $\begin{array}{l}{[134,150} \\
152,153]\end{array}$ \\
\hline $\begin{array}{l}\text { Dppa2 \& } \\
\text { Dppa4 }\end{array}$ & $\begin{array}{l}\text { Essential for ESC maintenance; } \\
\text { Putative target of Oct } 4 .\end{array}$ & {$[9,157,160]$} \\
\hline $\operatorname{Tbx} 3$ & $\begin{array}{l}\text { Activate Nanog, Oct4, Sox2, Sall4, Lefty1, Lefty2, Zfp 42, Klf2, Klf4, } \\
\text { Klf5, } n \text {-Myc and } c-M y c \text {; } \\
\text { Target of Nanog and Tcf3; } \\
\text { Partially activated by PI3-kinase but inhibited by MAP-kinase; } \\
\text { Repress the expression of cell cycle regulators } N F \kappa B I B \text { and } p 14^{A R F} \text {. }\end{array}$ & {$[87,170]$} \\
\hline PRDM14 & $\begin{array}{l}\text { Activate } O c t 4 \text { in human ESCs; } \\
\text { Repress differentiation-related genes; } \\
\text { Interact with PRC } 2 \text { complex to repress gene expression. }\end{array}$ & {$[175,177,178]$} \\
\hline L1td1 & $\begin{array}{l}\text { Interacts with Lin28 to modulate levels of Oct4; } \\
\text { Target of Oct4, Sox2, and Nanog in human ESCs. }\end{array}$ & {$[182]$} \\
\hline Utfl & $\begin{array}{l}\text { Direct target of Oct } 4 \text { and Sox } 2 \\
\text { Involved in chromatin-associated transcriptional repression. }\end{array}$ & {$[188,189]$} \\
\hline
\end{tabular}

\section{Acknowledgments}

This work was supported by grants from the Research Grants Council of Hong Kong (CUHK 464411 to B.F, CUHK 478812 to B.F.); and in part by funds from the National Natural Science Foundation of China (NSFC 31171433 to B.F.) and Shenzhen Research Fund for Three Focused Investment Areas (JC201104220293A to B.F.).

\section{Conflicts of Interest}

The authors declare no conflict of interest.

\section{References}

1. Evans, M.J.; Kaufman, M.H. Establishment in culture of pluripotential cells from mouse embryos. Nature 1981, 292, 154-156.

2. Takahashi, K.; Yamanaka, S. Induction of pluripotent stem cells from mouse embryonic and adult fibroblast cultures by defined factors. Cell 2006, 126, 663-676. 
3. Takahashi, K.; Tanabe, K.; Ohnuki, M.; Narita, M.; Ichisaka, T.; Tomoda, K.; Yamanaka, S. Induction of pluripotent stem cells from adult human fibroblasts by defined factors. Cell 2007, $131,861-872$.

4. Williams, R.L.; Hilton, D.J.; Pease, S.; Willson, T.A.; Stewart, C.L.; Gearing, D.P.; Wagner, E.F.; Metcalf, D.; Nicola, N.A.; Gough, N.M. Myeloid leukaemia inhibitory factor maintains the developmental potential of embryonic stem cells. Nature 1988, 336, 684-687.

5. Smith, A.G.A.; Heath, J.K.J.; Donaldson, D.D.D.; Wong, G.G.G.; Moreau, J.J.; Stahl, M.M.; Rogers, D.D. Inhibition of pluripotential embryonic stem cell differentiation by purified polypeptides. Nature 1988, 336, 688-690.

6. Ying, Q.-L.; Nichols, J.; Chambers, I.; Smith, A. BMP induction of Id proteins suppresses differentiation and sustains embryonic stem cell self-renewal in collaboration with STAT3. Cell 2003, 115, 281-292.

7. Ying, Q.-L.; Wray, J.; Nichols, J.; Batlle-Morera, L.; Doble, B.; Woodgett, J.; Cohen, P.; Smith, A. The ground state of embryonic stem cell self-renewal. Nature 2008, 453, 519-523.

8. Thomson, J.A.; Itskovitz-Eldor, J.; Shapiro, S.S.; Waknitz, M.A.; Swiergiel, J.J.; Marshall, V.S.; Jones, J.M. Embryonic stem cell lines derived from human blastocysts. Science 1998, 282, $1145-1147$.

9. Boyer, L.A.; Lee, T.I.; Cole, M.F.; Johnstone, S.E.; Levine, S.S.; Zucker, J.P.; Guenther, M.G.; Kumar, R.M.; Murray, H.L.; Jenner, R.G.; et al. Core transcriptional regulatory circuitry in human embryonic stem cells. Cell 2005, 122, 947-956.

10. Loh, Y.-H.; Wu, Q.; Chew, J.-L.; Vega, V.B.; Zhang, W.; Chen, X.; Bourque, G.; George, J.; Leong, B.; Liu, J.; et al. The Oct4 and Nanog transcription network regulates pluripotency in mouse embryonic stem cells. Nat. Genet. 2006, 38, 431-440.

11. Gaspar-Maia, A.; Alajem, A.; Meshorer, E.; Ramalho-Santos, M. Open chromatin in pluripotency and reprogramming. Nature 2011, 12, 36-47.

12. Liang, J.; Wan, M.; Zhang, Y.; Gu, P.; Xin, H.; Jung, S.Y.; Qin, J.; Wong, J.; Cooney, A.J.; Liu, D.; et al. Nanog and Oct4 associate with unique transcriptional repression complexes in embryonic stem cells. Nat. Cell Biol. 2008, 10, 731-739.

13. Tay, Y.; Zhang, J.; Thomson, A.M.; Lim, B.; Rigoutsos, I. MicroRNAs to Nanog, Oct4 and Sox2 coding regions modulate embryonic stem cell differentiation. Nature 2008, 455, 1124-1128.

14. Xu, N.; Papagiannakopoulos, T.; Pan, G.; Thomson, J.A.; Kosik, K.S. MicroRNA-145 regulates OCT4, SOX2, and KLF4 and represses pluripotency in human embryonic stem cells. Cell 2009; 137, 647-658.

15. Guttman, M.; Donaghey, J.; Carey, B.W.; Garber, M.; Grenier, J.K.; Munson, G.; Young, G.; Lucas, A.B.; Ach, R.; Bruhn, L.; et al. lincRNAs act in the circuitry controlling pluripotency and differentiation. Nature 2011, 477, 295-300.

16. Nichols, J.; Zevnik, B.; Anastassiadis, K.; Niwa, H.; Klewe-Nebenius, D.; Chambers, I.; Scholer, H.; Smith, A. Formation of pluripotent stem cells in the mammalian embryo depends on the POU transcription factor Oct4. Cell 1998, 95, 379-391.

17. Niwa, H.; Miyazaki, J.; Smith, A.G. Quantitative expression of Oct-3/4 defines differentiation, dedifferentiation or self-renewal of ES cells. Nat. Genet. 2000, 24, 372-376. 
18. Avilion, A.A.; Nicolis, S.K.; Pevny, L.H.; Perez, L.; Vivian, N.; Lovell-Badge, R. Multipotent cell lineages in early mouse development depend on SOX2 function. Genes Dev. 2003, 17, 126-140.

19. Ng, C.K.; Li, N.X.; Chee, S.; Prabhakar, S.; Kolatkar, P.R.; Jauch, R. Deciphering the Sox-Oct partner code by quantitative cooperativity measurements. Nucleic Acids Res. 2012, 40, 4933-4941.

20. Lodato, M.A.; Ng, C.W.; Wamstad, J.A.; Cheng, A.W.; Thai, K.K.; Fraenkel, E.; Jaenisch, R.; Boyer, L.A. SOX2 co-occupies distal enhancer elements with distinct POU factors in ESCs and NPCs to specify cell state. PLoS Genet. 2013, 9, e1003288.

21. Aksoy, I.; Jauch, R.; Chen, J.; Dyla, M.; Divakar, U.; Bogu, G.K.; Teo, R.; Leng Ng, C.K.; Herath, W.; Lili, S.; et al. Oct4 switches partnering from Sox2 to Sox17 to reinterpret the enhancer code and specify endoderm. EMBO J. 2013, 32, 938-953.

22. Chambers, I.; Colby, D.; Robertson, M.; Nichols, J.; Lee, S.; Tweedie, S.; Smith, A. Functional expression cloning of Nanog, a pluripotency sustaining factor in embryonic stem cells. Cell 2003, 113, 643-655.

23. Mitsui, K.; Tokuzawa, Y.; Itoh, H.; Segawa, K.; Murakami, M.; Takahashi, K.; Maruyama, M.; Maeda, M.; Yamanaka, S. The homeoprotein Nanog is required for maintenance of pluripotency in mouse epiblast and ES cells. Cell 2003, 113, 631-642.

24. Mizusaki, H. Dax-1 (Dosage-sensitive sex reversal-adrenal hypoplasia congenita critical region on the $\mathrm{X}$ chromosome, gene 1) gene transcription is regulated by Wnt4 in the female developing gonad. Mol. Endocrinol. 2003, 17, 507-519.

25. Chambers, I.; Silva, J.; Colby, D.; Nichols, J.; Nijmeijer, B.; Robertson, M.; Vrana, J.; Jones, K.; Grotewold, L.; Smith, A. Nanog safeguards pluripotency and mediates germline development. Nature 2007, 450, 1230-1234.

26. Jaenisch, R.; Young, R. Stem cells, the molecular circuitry of pluripotency and nuclear reprogramming. Cell 2008, 132, 567-582.

27. Young, R.A. Control of the embryonic stem cell state. Cell 2011, 144, 940-954.

28. Kim, J.; Chu, J.; Shen, X.; Wang, J.; Orkin, S.H. An extended transcriptional network for pluripotency of embryonic stem cells. Cell 2008, 132, 1049-1061.

29. Chen, X.; Xu, H.; Yuan, P.; Fang, F.; Huss, M.; Vega, V.B.; Wong, E.; Orlov, Y.L.; Zhang, W.; Jiang, J.; et al. Integration of external signaling pathways with the core transcriptional network in embryonic stem cells. Cell 2008, 133, 1106-1117.

30. Whyte, W.A.; Orlando, D.A.; Hnisz, D.; Abraham, B.J.; Lin, C.Y.; Kagey, M.H.; Rahl, P.B.; Lee, T.I.; Young, R.A. Master transcription factors and mediator establish super-enhancers at key cell identity genes. Cell 2013, 153, 307-319.

31. Laudet, V.; Gronemeyer, H. The Nuclear Receptor Factsbook; Academic Press: London, UK, 2001.

32. Robinson-Rechavi, M.M.; Carpentier, A.S.A.; Duffraisse, M.M.; Laudet, V.V. How many nuclear hormone receptors are there in the human genome? Trends Genet. 2001, 17, 554-556.

33. Robinson-Rechavi, M.; Laudet, V. Bioinformatics of nuclear receptors. Methods Enzymol. 2003, 364, 93-118.

34. McKenna, N.J.; O’Malley, B.W. Combinatorial control of gene expression by nuclear receptors and coregulators. Cell 2002, 108, 465-474. 
35. Robinson-Rechavi, M.; Garcia, H.E.; Laudet, V. The nuclear receptor superfamily. J. Cell Sci. 2003, 116, 585-586.

36. Niakan, K.K.; Davis, E.C.; Clipsham, R.C.; Jiang, M.; Dehart, D.B.; Sulik, K.K.; McCabe, E.R. Novel role for the orphan nuclear receptor Dax1 in embryogenesis, different from steroidogenesis. Mol. Genet. Metab. 2006, 88, 261-271.

37. Khalfallah, O.; Rouleau, M.; Barbry, P.; Bardoni, B.; Lalli, E. Dax-1 knockdown in mouse embryonic stem cells induces loss of pluripotency and multilineage differentiation. Stem Cells 2009, 27, 1529-1537.

38. Wagner, R.T.; Cooney, A.J. Minireview: The diverse roles of nuclear receptors in the regulation of embryonic stem cell pluripotency. Mol. Endocrinol. 2013, 27, 864-878.

39. Luo, J.; Sladek, R.; Bader, J.A.; Matthyssen, A.; Rossant, J.; Giguere, V. Placental abnormalities in mouse embryos lacking the orphan nuclear receptor ERR-beta. Nature 1997, 388, 778-782.

40. Mitsunaga, K.; Araki, K.; Mizusaki, H.; Morohashi, K.; Haruna, K.; Nakagata, N.; Giguere, V.; Yamamura, K.; Abe, K. Loss of PGC-specific expression of the orphan nuclear receptor ERR-beta results in reduction of germ cell number in mouse embryos. Mech. Dev. 2004, 121, 237-246.

41. Zhang, X.; Zhang, J.; Wang, T.; Esteban, M.A.; Pei, D. Esrrb activates Oct4 transcription and sustains self-renewal and pluripotency in embryonic stem cells. J. Biol. Chem. 2008, 283, 35825-35833.

42. Ivanova, N.; Dobrin, R.; Lu, R.; Kotenko, I.; Levorse, J.; DeCoste, C.; Schafer, X.; Lun, Y.; Lemischka, I.R. Dissecting self-renewal in stem cells with RNA interference. Nat. Cell Biol. 2006, 442, 533-538.

43. Feng, B.; Jiang, J.; Kraus, P.; Ng, J.H.; Heng, J.C.; Chan, Y.S.; Yaw, L.P.; Zhang, W.; Loh, Y.H.; Han, J.; et al. Reprogramming of fibroblasts into induced pluripotent stem cells with orphan nuclear receptor Esrrb. Nat. Cell Biol. 2009, 11, 197-203.

44. Van den Berg, D.L.; Zhang, W.; Yates, A.; Engelen, E.; Takacs, K.; Bezstarosti, K.; Demmers, J.; Chambers, I.; Poot, R.A. Estrogen-related receptor beta interacts with Oct4 to positively regulate Nanog gene expression. Mol. Cell Biol. 2008, 28, 5986-5995.

45. Hutchins, A.P.; Choo, S.H.; Mistri, T.K.; Rahmani, M.; Woon, C.T.; Ng, C.K.; Jauch, R.; Robson, P. Co-motif discovery identifies an Esrrb-Sox2-DNA ternary complex as a mediator of transcriptional differences between mouse embryonic and epiblast stem cells. Stem Cells 2013, 31, 269-281.

46. Percharde, M.; Lavial, F.; Ng, J.H.; Kumar, V.; Tomaz, R.A.; Martin, N.; Yeo, J.C.; Gil, J.; Prabhakar, S.; Ng, H.H.; et al. Ncoa3 functions as an essential Esrrb coactivator to sustain embryonic stem cell self-renewal and reprogramming. Genes Dev. 2012, 26, 2286-2298.

47. Festuccia, N.; Osorno, R.; Halbritter, F.; Karwacki-Neisius, V.; Navarro, P.; Colby, D.; Wong, F.; Yates, A.; Tomlinson, S.R.; Chambers, I. Esrrb is a direct Nanog target gene that can substitute for Nanog function in pluripotent cells. Cell Stem Cell 2012, 11, 477-490.

48. Martello, G.; Sugimoto, T.; Diamanti, E.; Joshi, A.; Hannah, R.; Ohtsuka, S.; Gottgens, B.; Niwa, H.; Smith, A. Esrrb is a pivotal target of the Gsk3/Tcf3 axis regulating embryonic stem cell self-renewal. Cell Stem Cell 2012, 11, 491-504. 
49. Paré, J.-F.; Malenfant, D.; Courtemanche, C.; Jacob-Wagner, M.; Roy, S.; Allard, D.; Bélanger, L. The fetoprotein transcription factor $(F T F)$ gene is essential to embryogenesis and cholesterol homeostasis and is regulated by a DR4 element. J. Biol. Chem. 2004, 279, 21206-21216.

50. Gu, P.; Goodwin, B.; Chung, A.C.; Xu, X.; Wheeler, D.A.; Price, R.R.; Galardi, C.; Peng, L.; Latour, A.M.; Koller, B.H.; et al. Orphan nuclear receptor LRH-1 is required to maintain Oct4 expression at the epiblast stage of embryonic development. Mol. Cell Biol. 2005, 25, 3492-3505.

51. Heng, J.C.; Feng, B.; Han, J.; Jiang, J.; Kraus, P.; Ng, J.H.; Orlov, Y.L.; Huss, M.; Yang, L.; Lufkin, T.; et al. The nuclear receptor Nr5a2 can replace Oct4 in the reprogramming of murine somatic cells to pluripotent cells. Cell Stem Cell 2010, 6, 167-174.

52. Guo, G.; Smith, A. A genome-wide screen in EpiSCs identifies Nr5a nuclear receptors as potent inducers of ground state pluripotency. Development 2010, 137, 3185-3192.

53. Kelly, V.R.; Xu, B.; Kuick, R.; Koenig, R.J.; Hammer, G.D. Daxl up-regulates Oct4 expression in mouse embryonic stem cells via LRH-1 and SRA. Mol. Endocrinol. 2010, 24, 2281-2291.

54. Wang, W.; Yang, J.; Liu, H.; Lu, D.; Chen, X.; Zenonos, Z.; Campos, L.S.; Rad, R.; Guo, G.; Zhang, S.; et al. Rapid and efficient reprogramming of somatic cells to induced pluripotent stem cells by retinoic acid receptor gamma and liver receptor homolog 1. Proc. Natl. Acad. Sci. USA 2011, 108, 18283-18288.

55. Wu, Z.; Yang, M.; Liu, H.; Guo, H.; Wang, Y.; Cheng, H.; Chen, L. Role of nuclear receptor coactivator 3 (Ncoa3) in pluripotency maintenance. J. Biol. Chem. 2012, 287, 38295-38304.

56. Jang, H.; Kim, T.W.; Yoon, S.; Choi, S.Y.; Kang, T.W.; Kim, S.Y.; Kwon, Y.W.; Cho, E.J.; Youn, H.D. O-GlcNAc regulates pluripotency and reprogramming by directly acting on core components of the pluripotency network. Cell Stem Cell 2012, 11, 62-74.

57. Wagner, R.T.; Xu, X.; Yi, F.; Merrill, B.J.; Cooney, A.J. Canonical Wnt/beta-catenin regulation of liver receptor homolog-1 mediates pluripotency gene expression. Stem Cells 2010, 28 , 1794-1804.

58. Yumoto, F.; Nguyen, P.; Sablin, E.P.; Baxter, J.D.; Webb, P.; Fletterick, R.J. Structural basis of coactivation of liver receptor homolog-1 by beta-catenin. Proc. Natl. Acad. Sci. USA 2012, 109, 143-148.

59. Zanaria, E.; Muscatelli, F.; Bardoni, B.; Strom, T.M.; Guioli, S.; Guo, W.; Lalli, E.; Moser, C.; Walker, A.P.; McCabe, E.R.; et al. An unusual member of the nuclear hormone receptor superfamily responsible for X-linked adrenal hypoplasia congenita. Nature 1994, 372, 635-641.

60. Lalli, E.; Sassone-Corsi, P. DAX-1, an unusual orphan receptor at the crossroads of steroidogenic function and sexual differentiation. Mol. Endocrinol. 2003, 17, 1445-1453.

61. Clipsham, R.; Niakan, K.; McCabe, E.R. Nr0b1 and its network partners are expressed early in murine embryos prior to steroidogenic axis organogenesis. Gene Expr. Patterns 2004, 4, 3-14.

62. Sun, C.; Nakatake, Y.; Akagi, T.; Ura, H.; Matsuda, T.; Nishiyama, A.; Koide, H.; Ko, M.S.; Niwa, H.; Yokota, T. Dax1 binds to Oct3/4 and inhibits its transcriptional activity in embryonic stem cells. Mol. Cell Biol. 2009, 29, 4574-4583.

63. Xu, B.; Yang, W.H.; Gerin, I.; Hu, C.D.; Hammer, G.D.; Koenig, R.J. Dax-1 and steroid receptor RNA activator (SRA) function as transcriptional coactivators for steroidogenic factor 1 in steroidogenesis. Mol. Cell Biol. 2009, 29, 1719-1734. 
64. Sablin, E.P.; Woods, A.; Krylova, I.N.; Hwang, P.; Ingraham, H.A.; Fletterick, R.J. The structure of corepressor Dax-1 bound to its target nuclear receptor LRH-1. Proc. Natl. Acad. Sci. USA 2008, $105,18390-18395$.

65. Wang, J.; Rao, S.; Chu, J.; Shen, X.; Levasseur, D.N.; Theunissen, T.W.; Orkin, S.H. A protein interaction network for pluripotency of embryonic stem cells. Nature 2006, 444, 364-368.

66. Sun, C.; Nakatake, Y.; Ura, H.; Akagi, T.; Niwa, H.; Koide, H.; Yokota, T. Stem cell-specific expression of Daxl is conferred by STAT3 and Oct3/4 in embryonic stem cells. Biochem. Biophys. Res. Commun. 2008, 372, 91-96.

67. Masui, S.; Nakatake, Y.; Toyooka, Y.; Shimosato, D.; Yagi, R.; Takahashi, K.; Okochi, H.; Okuda, A.; Matoba, R.; Sharov, A.A.; et al. Pluripotency governed by Sox2 via regulation of Oct3/4 expression in mouse embryonic stem cells. Nat. Cell Biol. 2007, 9, 625-635.

68. Kelly, V.R.; Hammer, G.D. LRH-1 and Nanog regulate Daxl transcription in mouse embryonic stem cells. Mol. Cell. Endocrinol. 2011, 332, 116-124.

69. Gu, P.; LeMenuet, D.; Chung, A.C.; Mancini, M.; Wheeler, D.A.; Cooney, A.J. Orphan nuclear receptor GCNF is required for the repression of pluripotency genes during retinoic acid-induced embryonic stem cell differentiation. Mol. Cell Biol. 2005, 25, 8507-8519.

70. Sattler, U.; Samochocki, M.; Maelicke, A.; Zechel, C. The expression level of the orphan nuclear receptor GCNF (germ cell nuclear factor) is critical for neuronal differentiation. Mol. Endocrinol. 2004, 18, 2714-2726.

71. Akamatsu, W.; DeVeale, B.; Okano, H.; Cooney, A.J.; van der Kooy, D. Suppression of Oct4 by germ cell nuclear factor restricts pluripotency and promotes neural stem cell development in the early neural lineage. J. Neurosci. 2009, 29, 2113-2124.

72. Wang, H.; Wang, X.; Xu, X.; Zwaka, T.P.; Cooney, A.J. Epigenetic Re-programming of the germ cell nuclear factor gene is required for proper differentiation of induced pluripotent cells. Stem Cells 2013, 31, 2659-2666.

73. Fuhrmann, G.; Chung, A.C.; Jackson, K.J.; Hummelke, G.; Baniahmad, A.; Sutter, J.; Sylvester, I.; Scholer, H.R.; Cooney, A.J. Mouse germline restriction of Oct4 expression by germ cell nuclear factor. Dev. Cell 2001, 1, 377-387.

74. Suske, G.; Bruford, E.; Philipsen, S. Mammalian $S P / K L F$ transcription factors: Bring in the family. Genomics 2005, 85, 551-556.

75. Philipsen, S.; Suske, G. A tale of three fingers: The family of mammalian $S p / X K L F$ transcription factors. Nucleic Acids Res. 1999, 27, 2991-3000.

76. Mahatan, C.S.; Kaestner, K.H.; Geiman, D.E.; Yang, V.W. Characterization of the structure and regulation of the murine gene encoding gut-enriched Kruppel-like factor (Kruppel-like factor 4). Nucleic Acids Res. 1999, 27, 4562-4569.

77. Jiang, J.; Chan, Y.-S.; Loh, Y.-H.; Cai, J.; Tong, G.-Q.; Lim, C.-A.; Robson, P.; Zhong, S.; $\mathrm{Ng}, \mathrm{H} .-\mathrm{H}$. A core Klf circuitry regulates self-renewal of embryonic stem cells. Nat. Cell Biol. 2008, 10, 353-360.

78. Nakagawa, M.; Koyanagi, M.; Tanabe, K.; Takahashi, K.; Ichisaka, T.; Aoi, T.; Okita, K.; Mochiduki, Y.; Takizawa, N.; Yamanaka, S. Generation of induced pluripotent stem cells without Myc from mouse and human fibroblasts. Nat. Biotechnol. 2008, 26, 101-106. 
79. Chan, K.K.; Zhang, J.; Chia, N.Y.; Chan, Y.S.; Sim, H.S.; Tan, K.S.; Oh, S.K.; Ng, H.H.; Choo, A.B. KLF4 and PBXI directly regulate $N A N O G$ expression in human embryonic stem cells. Stem Cells 2009, 27, 2114-2125.

80. Wei, Z.; Yang, Y.; Zhang, P.; Andrianakos, R.; Hasegawa, K.; Lyu, J.; Chen, X.; Bai, G.; Liu, C.; Pera, M.; et al. Klf4 interacts directly with Oct4 and Sox2 to promote reprogramming. Stem Cells 2009, 27, 2969-2978.

81. Li, Y.; McClintick, J.; Zhong, L.; Edenberg, H.J.; Yoder, M.C.; Chan, R.J. Murine embryonic stem cell differentiation is promoted by SOCS-3 and inhibited by the zinc finger transcription factor Klf4. Blood 2005, 105, 635-637.

82. Zhang, P.; Andrianakos, R.; Yang, Y.; Liu, C.; Lu, W. Kruppel-like factor 4 (Klf4) prevents embryonic stem (ES) cell differentiation by regulating Nanog gene expression. J. Biol. Chem. 2010, 285, 9180-9189.

83. Nakatake, Y.; Fukui, N.; Iwamatsu, Y.; Masui, S.; Takahashi, K.; Yagi, R.; Yagi, K.; Miyazaki, J.; Matoba, R.; Ko, M.S.; et al. Klf4 cooperates with Oct3/4 and Sox2 to activate the Leftyl core promoter in embryonic stem cells. Mol. Cell Biol. 2006, 26, 7772-7782.

84. Sridharan, R.; Tchieu, J.; Mason, M.J.; Yachechko, R.; Kuoy, E.; Horvath, S.; Zhou, Q.; Plath, K. Role of the murine reprogramming factors in the induction of pluripotency. Cell 2009, 136, 364-377.

85. Hall, J.; Guo, G.; Wray, J.; Eyres, I.; Nichols, J.; Grotewold, L.; Morfopoulou, S.; Humphreys, P.; Mansfield, W.; Walker, R.; et al. Oct4 and LIF/Stat3 additively induce Krüppel factors to sustain embryonic stem cell self-renewal. Cell Stem Cell 2009, 5, 597-609.

86. Guo, G.; Yang, J.; Nichols, J.; Hall, J.S.; Eyres, I.; Mansfield, W.; Smith, A. Klf4 reverts developmentally programmed restriction of ground state pluripotency. Development 2009, 136, 1063-1069.

87. Niwa, H.; Ogawa, K.; Shimosato, D.; Adachi, K. A parallel circuit of LIF signalling pathways maintains pluripotency of mouse ES cells. Nature 2009, 460, 118-122.

88. Ema, M.; Mori, D.; Niwa, H.; Hasegawa, Y.; Yamanaka, Y.; Hitoshi, S.; Mimura, J.; Kawabe, Y.; Hosoya, T.; Morita, M.; et al. Krüppel-like factor 5 is essential for blastocyst development and the normal self-renewal of mouse ESCs. Cell Stem Cell 2008, 3, 555-567.

89. Segre, J.A.; Bauer, C.; Fuchs, E. Klf4 is a transcription factor required for establishing the barrier function of the skin. Nat. Genet. 1999, 22, 356-360.

90. Lee, J.S.; Yu, Q.; Shin, J.T.; Sebzda, E.; Bertozzi, C.; Chen, M.; Mericko, P.; Stadtfeld, M.; Zhou, D.; Cheng, L.; et al. Klf2 is an essential regulator of vascular hemodynamic forces in vivo. Dev. Cell 2006, 11, 845-857.

91. Wani, M.A.; Means, R.T.; Lingrel, J.B. Loss of LKLF function results in embryonic lethality in mice. Transgenic Res. 1998, 7, 229-238.

92. Yoshikawa, T.; Piao, Y.; Zhong, J.; Matoba, R.; Carter, M.G.; Wang, Y.; Goldberg, I.; Ko, M.S. High-throughput screen for genes predominantly expressed in the ICM of mouse blastocysts by whole mount in situ hybridization. Gene Expr. Patterns 2006, 6, 213-224.

93. Kohlhase, J.; Heinrich, M.; Liebers, M.; Fröhlich Archangelo, L.; Reardon, W.; Kispert, A. Cloning and expression analysis of SALL4, the murine homologue of the gene mutated in Okihiro syndrome. Cytogenet. Genome Res. 2002, 98, 274-277. 
94. Elling, U.; Klasen, C.; Eisenberger, T.; Anlag, K.; Treier, M. Murine inner cell mass-derived lineages depend on Sall4 function. Proc. Natl. Acad. Sci. USA 2006, 103, 16319-16324.

95. Warren, M.; Wang, W.; Spiden, S.; Chen-Murchie, D.; Tannahill, D.; Steel, K.P.; Bradley, A. A Sall4 mutant mouse model useful for studying the role of Sall4 in early embryonic development and organogenesis. Genesis 2007, 45, 51-58.

96. Sakaki-Yumoto, M.; Kobayashi, C.; Sato, A.; Fujimura, S.; Matsumoto, Y.; Takasato, M.; Kodama, T.; Aburatani, H.; Asashima, M.; Yoshida, N.; et al. The murine homolog of SALL4, a causative gene in Okihiro syndrome, is essential for embryonic stem cell proliferation, and cooperates with Sall1 in anorectal, heart, brain and kidney development. Development 2006, 133, 3005-3013.

97. Rao, S.; Zhen, S.; Roumiantsev, S.; McDonald, L.T.; Yuan, G.C.; Orkin, S.H. Differential roles of Sall4 isoforms in embryonic stem cell pluripotency. Mol. Cell Biol. 2010, 30, 5364-5380.

98. Lu, J.; Jeong, H.W.; Kong, N.; Yang, Y.; Carroll, J.; Luo, H.R.; Silberstein, L.E.; Yupoma; Chai, L. Stem cell factor SALL4 represses the transcriptions of PTEN and SALL1 through an epigenetic repressor complex. PLoS One 2009, 4, e5577.

99. Zhang, J.; Tam, W.-L.; Tong, G.-Q.; Wu, Q.; Chan, H.-Y.; Soh, B.-S.; Lou, Y.; Yang, J.; Ma, Y.; Chai, L.; et al. Sall4 modulates embryonic stem cell pluripotency and early embryonic development by the transcriptional regulation of Pou5f1. Nat. Cell Biol. 2006, 8, 1114-1123.

100. Van den Berg, D.L.C.; Snoek, T.; Mullin, N.P.; Yates, A.; Bezstarosti, K.; Demmers, J.; Chambers, I.; Poot, R.A. An Oct4-centered protein interaction network in embryonic stem cells. Cell Stem Cell. 2010, 6, 369-381.

101. Tanimura, N.; Saito, M.; Ebisuya, M.; Nishida, E.; Ishikawa, F. Stemness-related factor Sall4 interacts with transcription factors Oct-3/4 and Sox 2 and occupies Oct-Sox elements in mouse embryonic stem cells. J. Biol. Chem. 2013, 288, 5027-5038.

102. Wu, Q.; Chen, X.; Zhang, J.; Loh, Y.-H.; Low, T.-Y.; Zhang, W.; Zhang, W.; Sze, S.-K.; Lim, B.; $\mathrm{Ng}, \mathrm{H} .-\mathrm{H}$. Sall4 interacts with Nanog and co-occupies Nanog genomic sites in embryonic stem cells. J. Biol. Chem. 2006, 281, 24090-24094.

103. Nishiyama, A.; Sharov, A.A.; Piao, Y.; Amano, M.; Amano, T.; Hoang, H.G.; Binder, B.Y.; Tapnio, R.; Bassey, U.; Malinou, J.N.; et al. Systematic repression of transcription factors reveals limited patterns of gene expression changes in ES cells. Sci. Rep. 2013, 3, 1390.

104. Tsubooka, N.; Ichisaka, T.; Okita, K.; Takahashi, K.; Nakagawa, M.; Yamanaka, S. Roles of Sall4 in the generation of pluripotent stem cells from blastocysts and fibroblasts. Genes Cells 2009, 14, 683-694.

105. Yang, J.; Corsello, T.R.; Ma, Y. Stem cell gene SALL4 suppresses transcription through recruitment of DNA methyltransferases. J. Biol. Chem. 2012, 287, 1996-2005.

106. Böhm, J.; Kaiser, F.J.; Borozdin, W.; Depping, R.; Kohlhase, J. Synergistic cooperation of Sall4 and Cyclin D1 in transcriptional repression. Biochem. Biophys. Res. Commun. 2007, 356, 773-779.

107. Yang, J.; Gao, C.; Chai, L.; Ma, Y. A novel SALL4/OCT4 transcriptional feedback network for pluripotency of embryonic stem cells. PLoS One 2010, 5, e10766.

108. Katoh, M. Human FOX gene family (Review). Int. J. Oncol. 2004, 25, 1495-1500.

109. Hanna, L.A.; Foreman, R.K.; Tarasenko, I.A.; Kessler, D.S.; Labosky, P.A. Requirement for Foxd3 in maintaining pluripotent cells of the early mouse embryo. Genes Dev. 2002, 16, 2650-2661. 
110. Tompers, D.M.; Foreman, R.K.; Wang, Q.; Kumanova, M.; Labosky, P.A. Foxd3 is required in the trophoblast progenitor cell lineage of the mouse embryo. Dev. Biol. 2005, 285, 126-137.

111. Galán, A.A.; Montaner, D.D.; Póo, M.E.M.; Valbuena, D.D.; Ruiz, V.V.; Aguilar, C.C.; Dopazo, J.J.; Simón, C.C. Functional genomics of 5- to 8-cell stage human embryos by blastomere single-cell cDNA analysis. PLoS One 2009, 5, e13615.

112. Sperger, J.M.; Chen, X.; Draper, J.S.; Antosiewicz, J.E.; Chon, C.H.; Jones, S.B.; Brooks, J.D.; Andrews, P.W.; Brown, P.O.; Thomson, J.A. Gene expression patterns in human embryonic stem cells and human pluripotent germ cell tumors. Proc. Natl. Acad. Sci. USA 2003, 100, 13350-13355.

113. Ginis, I.; Luo, Y.; Miura, T.; Thies, S.; Brandenberger, R.; Gerecht-Nir, S.; Amit, M.; Hoke, A.; Carpenter, M.K.; Itskovitz-Eldor, J.; et al. Differences between human and mouse embryonic stem cells. Dev. Biol. 2004, 269, 360-380.

114. Liu, Y.; Labosky, P.A. Regulation of embryonic stem cell self-renewal and pluripotency by Foxd3. Stem Cells 2008, 26, 2475-2484.

115. Arduini, B.L.; Brivanlou, A.H. Modulation of FOXD3 activity in human embryonic stem cells directs pluripotency and paraxial mesoderm fates. Stem Cells 2012, 30, 2188-2198.

116. Pan, G.; Li, J.; Zhou, Y.; Zheng, H.; Pei, D. A negative feedback loop of transcription factors that controls stem cell pluripotency and self-renewal. FASEB J. 2006, 20, 1730-1732.

117. Guo, Y.; Costa, R.; Ramsey, H.; Starnes, T.; Vance, G.; Robertson, K.; Kelley, M.; Reinbold, R.; Scholer, H.; Hromas, R. The embryonic stem cell transcription factors Oct-4 and FoxD3 interact to regulate endodermal-specific promoter expression. Proc. Natl. Acad. Sci. USA 2002, 99, 3663-3667.

118. Brandenberger, R.; Wei, H.; Zhang, S.; Lei, S.; Murage, J.; Fisk, G.J.; Li, Y.; Xu, C.; Fang, R.; Guegler, K.; et al. Transcriptome characterization elucidates signaling networks that control human ES cell growth and differentiation. Nat. Biotechnol. 2004, 22, 707-716.

119. Hoodless, P.A.; Pye, M.; Chazaud, C.; Labbe, E.; Attisano, L.; Rossant, J.; Wrana, J.L. FoxH1 (Fast) functions to specify the anterior primitive streak in the mouse. Genes Dev. 2001, 15, $1257-1271$.

120. Norris, D.P.; Brennan, J.; Bikoff, E.K.; Robertson, E.J. The Foxh1-dependent autoregulatory enhancer controls the level of Nodal signals in the mouse embryo. Development 2002, 129, 3455-3468.

121. Slagle, C.E.; Aoki, T.; Burdine, R.D. Nodal-dependent mesendoderm specification requires the combinatorial activities of FoxH1 and Eomesodermin. PLoS Genet. 2011, 7, e1002072.

122. Zhang, X.; Yalcin, S.; Lee, D.-F.; Yeh, T.-Y.J.; Lee, S.-M.; Su, J.; Mungamuri, S.K.; Rimmelé, P.; Kennedy, M.; Sellers, R.; et al. FOXO1 is an essential regulator of pluripotency in human embryonic stem cells. Nat. Cell Biol. 2011, 13, 1092-1099.

123. Brunet, A.; Bonni, A.; Zigmond, M.J.; Lin, M.Z.; Juo, P.; Hu, L.S.; Anderson, M.J.; Arden, K.C.; Blenis, J.; Greenberg, M.E. Akt promotes cell survival by phosphorylating and inhibiting a Forkhead transcription factor. Cell 1999, 96, 857-868.

124. Hosaka, T.; Biggs, W.H., 3rd; Tieu, D.; Boyer, A.D.; Varki, N.M.; Cavenee, W.K.; Arden, K.C. Disruption of forkhead transcription factor (FOXO) family members in mice reveals their functional diversification. Proc. Natl. Acad. Sci. USA 2004, 101, 2975-2980. 
125. Gabut, M.; Samavarchi-Tehrani, P.; Wang, X.; Slobodeniuc, V.; O’Hanlon, D.; Sung, H.K.; Alvarez, M.; Talukder, S.; Pan, Q.; Mazzoni, E.O.; et al. An alternative splicing switch regulates embryonic stem cell pluripotency and reprogramming. Cell 2011, 147, 132-146.

126. Zhang, Y.; Li, S.; Yuan, L.; Tian, Y.; Weidenfeld, J.; Yang, J.; Liu, F.; Chokas, A.L.; Morrisey, E.E. Foxp1 coordinates cardiomyocyte proliferation through both cell-autonomous and nonautonomous mechanisms. Genes Dev. 2010, 24, 1746-1757.

127. Wang, B.; Weidenfeld, J.; Lu, M.M.; Maika, S.; Kuziel, W.A.; Morrisey, E.E.; Tucker, P.W. Foxp1 regulates cardiac outflow tract, endocardial cushion morphogenesis and myocyte proliferation and maturation. Development 2004, 131, 4477-4487.

128. Wei, C.-L.; Miura, T.; Robson, P.; Lim, S.-K.; Xu, X.-Q.; Lee, M.Y.-C.; Gupta, S.; Stanton, L.; Luo, Y.; Schmitt, J.; et al. Transcriptome profiling of human and murine ESCs identifies divergent paths required to maintain the stem cell state. Stem Cells 2005, 23, 166-185.

129. Wang, Z.-X.; Kueh, J.L.L.; Teh, C.H.-L.; Rossbach, M.; Lim, L.; Li, P.; Wong, K.-Y.; Lufkin, T.; Robson, P.; Stanton, L.W. Zfp206 is a transcription factor that controls pluripotency of embryonic stem cells. Stem Cells 2007, 25, 2173-2182.

130. Yu, H.b.; Kunarso, G.; Hong, F.H.; Stanton, L.W. Zfp206, Oct4, and Sox2 are integrated components of a transcriptional regulatory network in embryonic stem cells. J. Biol. Chem. 2009, 284, 31327-31335.

131. Wang, Z.-X.; Teh, C.H.-L.; Kueh, J.L.L.; Lufkin, T.; Robson, P.; Stanton, L.W. Oct4 and Sox2 directly regulate expression of another pluripotency transcription factor, Zfp206, in embryonic stem cells. J. Biol. Chem. 2007, 282, 12822-12830.

132. Edelstein, L.C.; Collins, T. The SCAN domain family of zinc finger transcription factors. Gene 2005, 359, 1-17.

133. Liang, Y.; Huimei Hong, F.; Ganesan, P.; Jiang, S.; Jauch, R.; Stanton, L.W.; Kolatkar, P.R. Structural analysis and dimerization profile of the SCAN domain of the pluripotency factor Zfp206. Nucleic Acids Res. 2012, 40, 8721-8732.

134. Zalzman, M.; Falco, G.; Sharova, L.V.; Nishiyama, A.; Thomas, M.; Lee, S.-L.; Stagg, C.A.; Hoang, H.G.; Yang, H.-T.; Indig, F.E.; et al. Zscan4 regulates telomere elongation and genomic stability in ES cells. Nature 2010, 464, 858-863.

135. Casademunt, E.; Carter, B.D.; Benzel, I.; Frade, J.M.; Dechant, G.; Barde, Y.A. The zinc finger protein NRIF interacts with the neurotrophin receptor $\mathrm{p} 75(\mathrm{NTR})$ and participates in programmed cell death. EMBO J. 1999, 18, 6050-6061.

136. Rogers, M.B.; Hosler, B.A.; Gudas, L.J. Specific expression of a retinoic acid-regulated, zinc-finger gene, Rex-1, in preimplantation embryos, trophoblast and spermatocytes. Development 1991, 113, 815-824.

137. Eiges, R.; Schuldiner, M.; Drukker, M.; Yanuka, O.; Itskovitz-Eldor, J.; Benvenisty, N. Establishment of human embryonic stem cell-transfected clones carrying a marker for undifferentiated cells. Curr. Biol. 2001, 11, 514-518.

138. Cavalli, L.R.; Liang, B.C. Mutagenesis, tumorigenicity, and apoptosis: Are the mitochondria involved? Mutat. Res. 1998, 398, 19-26. 
139. Hosler, B.A.; Rogers, M.B.; Kozak, C.A.; Gudas, L.J. An octamer motif contributes to the expression of the retinoic acid-regulated zinc finger gene Rex-1 (Zfp-42) in F9 teratocarcinoma cells. Mol. Cell. Biol. 1993, 13, 2919-2928.

140. Shi, W. Regulation of the pluripotency marker Rex-1 by nanog and Sox2. J. Biol. Chem. 2006, 281, 23319-23325.

141. Rezende, N.C.; Lee, M.-Y.; Monette, S.; Mark, W.; Lu, A.; Gudas, L.J. Rex1 (Zfp42) null mice show impaired testicular function, abnormal testis morphology, and aberrant gene expression. Devel. Biol. 2011, 356, 370-382.

142. Masui, S.; Ohtsuka, S.; Yagi, R.; Takahashi, K.; Ko, M.S.; Niwa, H. Rex1/Zfp42 is dispensable for pluripotency in mouse ES cells. BMC Dev. Biol. 2008, 8, 45.

143. Scotland, K.B.; Chen, S.; Sylvester, R.; Gudas, L.J. Analysis of Rex1 (zfp42) function in embryonic stem cell differentiation. Dev. Dyn. 2009, 238, 1863-1877.

144. Gontan, C.; Achame, E.M.; Demmers, J.; Barakat, T.S.; Rentmeester, E.; van IJcken, W.; Grootegoed, J.A.; Gribnau, J. RNF12 initiates X-chromosome inactivation by targeting REX1 for degradation. Nature 2012, 485, 386-390.

145. Kim, J.D.; Kim, H.; Ekram, M.B.; Yu, S.; Faulk, C.; Kim, J. Rex1/Zfp42 as an epigenetic regulator for genomic imprinting. Hum. Mol. Genet. 2011, 20, 1353-1362.

146. Son, M.Y.; Choi, H.; Han, Y.-M.; Cho, Y.S. Unveiling the critical role of REX1 in the regulation of human stem cell pluripotency. Stem Cells 2013, 31, 2374-2387.

147. Falco, G.; Lee, S.-L.; Stanghellini, I.; Bassey, U.C.; Hamatani, T.; Ko, M.S.H. Zscan4: A novel gene expressed exclusively in late 2-cell embryos and embryonic stem cells. Dev. Biol. 2007, 307, 539-550.

148. Carter, M.G.; Stagg, C.A.; Falco, G.; Yoshikawa, T.; Bassey, U.C.; Aiba, K.; Sharova, L.V.; Shaik, N.; Ko, M.S.H. An in situ hybridization-based screen for heterogeneously expressed genes in mouse ES cells. Gene Expr. Patterns 2008, 8, 181-198.

149. Storm, M.P.; Kumpfmueller, B.; Thompson, B.; Kolde, R.; Vilo, J.; Hummel, O.; Schulz, H.; Welham, M.J. Characterization of the phosphoinositide 3-kinase-dependent transcriptome in murine embryonic stem cells: Identification of novel regulators of pluripotency. Stem Cells $\mathbf{2 0 0 9}$, $27,764-775$.

150. Jiang, J.; Lv, W.; Ye, X.; Wang, L.; Zhang, M.; Yang, H.; Okuka, M.; Zhou, C.; Zhang, X.; Liu, L.; et al. Zscan4 promotes genomic stability during reprogramming and dramatically improves the quality of iPS cells as demonstrated by tetraploid complementation. Cell Res. 2012, 23, 92-106.

151. Suda, Y.; Suzuki, M.; Ikawa, Y.; Aizawa, S. Mouse embryonic stem cells exhibit indefinite proliferative potential. J. Cell. Physiol. 1987, 133, 197-201.

152. Amano, T.; Hirata, T.; Falco, G.; Monti, M.; Sharova, L.V.; Amano, M.; Sheer, S.; Hoang, H.G.; Piao, Y.; Stagg, C.A.; et al. Zscan4 restores the developmental potency of embryonic stem cells. Nat. Commun. 2013, 4, 1-10.

153. Hirata, T.; Amano, T.; Nakatake, Y.; Amano, M.; Piao, Y.; Hoang, H.G.; Ko, M.S.H. Zscan4 transiently reactivates early embryonic genes during the generation of induced pluripotent stem cells. Sci. Rep. 2012, doi:10.1038/srep00208. 
154. Fischedick, G.; Klein, D.C.; Wu, G.; Esch, D.; Höing, S.; Han, D.W.; Reinhardt, P.; Hergarten, K.; Tapia, N.; Schöler, H.R.; et al. Zfp296 is a Novel, pluripotent-specific reprogramming factor. PLoS One 2012, 7, e34645.

155. Wang, Z.-X.; Teh, C.H.-L.; Chan, C.M.-Y.; Chu, C.; Rossbach, M.; Kunarso, G.; Allapitchay, T.B.; Wong, K.-Y.; Stanton, L.W. The transcription factor Zfp281 controls embryonic stem cell pluripotency by direct activation and repression of target genes. Stem Cells 2008, 26, 2791-2799.

156. Chen, X.; Fang, F.; Liou, Y.-C.; Ng, H.-H. Zfp143 regulates Nanog through modulation of Oct4 binding. Stem Cells 2008, 26, 2759-2767.

157. Maldonado-Saldivia, J.; van den Bergen, J.; Krouskos, M.; Gilchrist, M.; Lee, C.; Li, R.; Sinclair, A.H.; Surani, M.A.; Western, P.S. Dppa2 and Dppa4 are closely linked SAP motif genes restricted to pluripotent cells and the germ line. Stem Cells 2007, 25, 19-28.

158. Shin, M.-R.; Cui, X.-S.; Jun, J.-H.; Jeong, Y.-J.; Kim, N.-H. Identification of mouse blastocyst genes that are downregulated by double-stranded RNA-mediated knockdown of Oct-4 expression. Mol. Reprod. Dev. 2005, 70, 390-396.

159. Ko, M.S.; Kitchen, J.R.; Wang, X.; Threat, T.A.; Wang, X.; Hasegawa, A.; Sun, T.; Grahovac, M.J.; Kargul, G.J.; Lim, M.K.; et al. Large-scale cDNA analysis reveals phased gene expression patterns during preimplantation mouse development. Development 2000, 127, 1737-1749.

160. Aravind, L.; Koonin, E.V. SAP-A putative DNA-binding motif involved in chromosomal organization. Trends Biochem. Sci. 2000, 25, 112-114.

161. Du, J.; Chen, T.; Zou, X.; Xiong, B.; Lu, G. Dppa2 knockdown-induced differentiation and repressed proliferation of mouse embryonic stem cells. J. Biochem. 2010, 147, 265-271.

162. Masaki, H.; Nishida, T.; Kitajima, S.; Asahina, K.; Teraoka, H. Developmental pluripotency-associated 4 (DPPA4) localized in active chromatin inhibits mouse embryonic stem cell differentiation into a primitive ectoderm lineage. J. Biol. Chem. 2007, 282, 33034-33042.

163. Saitou, M.; Barton, S.C.; Surani, M.A. A molecular programme for the specification of germ cell fate in mice. Nature 2002, 418, 293-300.

164. Payer, B.; Chuva de Sousa Lopes, S.M.; Barton, S.C.; Lee, C.; Saitou, M.; Surani, M.A. Generation of stella-GFP transgenic mice: A novel tool to study germ cell development. Genesis 2006, 44, 75-83.

165. Payer, B.; Saitou, M.; Barton, S.C.; Thresher, R.; Dixon, J.P.C.; Zahn, D.; Colledge, W.H.; Carlton, M.B.L.; Nakano, T.; Surani, M.A. Stella is a maternal effect gene required for normal early development in mice. Curr. Biol. 2003, 13, 2110-2117.

166. Clark, A.T.; Rodriguez, R.T.; Bodnar, M.S.; Abeyta, M.J.; Cedars, M.I.; Turek, P.J.; Firpo, M.T.; Reijo Pera, R.A. Human STELLAR, NANOG, and GDF3 genes are expressed in pluripotent cells and map to chromosome 12p13, a hotspot for teratocarcinoma. Stem Cells 2004, 22, 169-179.

167. Hayashi, K.; Lopes, S.M.; Tang, F.; Surani, M.A. Dynamic equilibrium and heterogeneity of mouse pluripotent stem cells with distinct functional and epigenetic states. Cell Stem Cell 2008, 3, 391-401.

168. Amano, H.; Itakura, K.; Maruyama, M.; Ichisaka, T.; Nakagawa, M.; Yamanaka, S. Identification and targeted disruption of the mouse gene encoding ESG1 (PH34/ECAT2/DPPA5). BMC Dev. Biol. 2005, 6,11 . 
169. Davenport, T.G.T.; Jerome-Majewska, L.A.L.; Papaioannou, V.E.V. Mammary gland, limb and yolk sac defects in mice lacking $T b x 3$, the gene mutated in human ulnar mammary syndrome. Development 2003, 130, 2263-2273.

170. Han, J.; Yuan, P.; Yang, H.; Zhang, J.; Soh, B.-S.; Li, P.; Lim, S.L.; Cao, S.; Tay, J.; Orlov, Y.L.; et al. Tbx3 improves the germ-line competency of induced pluripotent stem cells. Nature 2010, 463, 1096-1100.

171. Esmailpour, T.; Huang, T. TBX3 promotes human embryonic stem cell proliferation and neuroepithelial differentiation in a differentiation stage-dependent manner. Stem Cells 2012, 30, 2152-2163.

172. Matsui, Y.; Zsebo, K.; Hogan, B.L. Derivation of pluripotential embryonic stem cells from murine primordial germ cells in culture. Cell 1992, 70, 841-847.

173. Ng, J.H.; Kumar, V.; Muratani, M.; Kraus, P.; Yeo, J.C.; Yaw, L.P.; Xue, K.; Lufkin, T.; Prabhakar, S.; Ng, H.H. In vivo epigenomic profiling of germ cells reveals germ cell molecular signatures. Dev. Cell 2013, 24, 324-333.

174. Imamura, M.; Miura, K.; Iwabuchi, K.; Ichisaka, T.; Nakagawa, M.; Lee, J.; Kanatsu-Shinohara, M.; Shinohara, T.; Yamanaka, S. Transcriptional repression and DNA hypermethylation of a small set of ES cell marker genes in male germline stem cells. BMC Dev. Biol. 2006, 6, 34.

175. Chia, N.-Y.; Chan, Y.-S.; Feng, B.; Lu, X.; Orlov, Y.L.; Moreau, D.; Kumar, P.; Yang, L.; Jiang, J.; Lau, M.-S.; et al. A genome-wide RNAi screen reveals determinants of human embryonic stem cell identity. Nature 2010, 468, 316-320.

176. Tsuneyoshi, N.; Sumi, T.; Onda, H.; Nojima, H.; Nakatsuji, N.; Suemori, H. PRDM14 suppresses expression of differentiation marker genes in human embryonic stem cells. Biochem. Biophys. Res. Commun. 2008, 367, 899-905.

177. Chan, Y.-S.; Göke, J.; Lu, X.; Venkatesan, N.; Feng, B.; Su, I.-H.; Ng, H.-H. A PRC2-dependent repressive role of PRDM14 in human embryonic stem cells and induced pluripotent stem cell reprogramming. Stem Cells 2013, 31, 682-692.

178. Yamaji, M.; Ueda, J.; Hayashi, K.; Ohta, H.; Yabuta, Y.; Kurimoto, K.; Nakato, R.; Yamada, Y.; Shirahige, K.; Saitou, M. PRDM14 ensures naive pluripotency through dual regulation of signaling and epigenetic pathways in mouse embryonic stem cells. Stem Cell 2013, 12, 368-382.

179. Yamaji, M.; Seki, Y.; Kurimoto, K.; Yabuta, Y.; Yuasa, M.; Shigeta, M.; Yamanaka, K.; Ohinata, Y.; Saitou, M. Critical function of Prdm14 for the establishment of the germ cell lineage in mice. Nat. Genet. 2008, 40, 1016-1022.

180. Grabole, N.; Tischler, J.; Hackett, J.A.; Kim, S.; Tang, F.; Leitch, H.G.; Magnúsdóttir, E.; Surani, M.A. Prdm14 promotes germline fate and naive pluripotency by repressing FGF signalling and DNA methylation. Nature 2013, 14, 629-637.

181. Iwabuchi, K.A.; Yamakawa, T.; Sato, Y.; Ichisaka, T. ECAT11/L1td1 is enriched in ESCs and rapidly activated during iPSC generation, but it is dispensable for the maintenance and induction of pluripotency. PLoS One 2011, 6, e20461.

182. Närvä, E.; Rahkonen, N.; Emani, M.R.; Lund, R.; Pursiheimo, J.-P.; Nästi, J.; Autio, R.; Rasool, O.; Denessiouk, K.; Lähdesmäki, H.; et al. RNA-binding protein L1TD1 interacts with LIN28 via RNA and is required for human embryonic stem cell self-renewal and cancer cell proliferation. Stem Cells 2012, 30, 452-460. 
183. Chuva de Sousa Lopes, S.M.; van den Driesche, S.; Carvalho, R.L.C.; Larsson, J.; Eggen, B.; Surani, M.A.; Mummery, C.L. Altered primordial germ cell migration in the absence of transforming growth factor beta signaling via ALK5. Dev. Biol. 2005, 284, 194-203.

184. Van Bragt, M.P.A.; Roepers-Gajadien, H.L.; Korver, C.M.; Bogerd, J.; Okuda, A.; Eggen, B.J.L.; de Rooij, D.G.; van Pelt, A.M.M. Expression of the pluripotency marker UTF1 is restricted to a subpopulation of early a spermatogonia in rat testis. Reproduction 2008, 136, 33-40.

185. Kristensen, D.M.; Nielsen, J.E.; Skakkebaek, N.E.; Graem, N.; Jacobsen, G.K.; Rajpert-De Meyts, E.; Leffers, H. Presumed pluripotency markers UTF-1 and REX-1 are expressed in human adult testes and germ cell neoplasms. Hum. Reprod. 2008, 23, 775-782.

186. Okuda, A.; Fukushima, A.; Nishimoto, M.; Orimo, A.; Yamagishi, T.; Nabeshima, Y.; Kuro-o, M.; Nabeshima, Y.-i.; Boon, K.; Keaveney, M.; et al. UTF1, a novel transcriptional coactivator expressed in pluripotent embryonic stem cells and extra-embryonic cells. EMBO J. 1998, 17, 2019-2032.

187. Nishimoto, M.; Miyagi, S.; Yamagishi, T.; Sakaguchi, T.; Niwa, H.; Muramatsu, M.; Okuda, A. Oct-3/4 maintains the proliferative embryonic stem cell state via specific binding to a variant octamer sequence in the regulatory region of the UTF1 locus. Mol. Cell. Biol. 2005, 25, 5084-5094.

188. Van den Boom, V.; Kooistra, S.M.; Boesjes, M.; Geverts, B.; Houtsmuller, A.B.; Monzen, K.; Komuro, I.; Essers, J.; Drenth-Diephuis, L.J.; Eggen, B.J.L. UTF1 is a chromatin-associated protein involved in ES cell differentiation. J. Cell Biol. 2007, 178, 913-924.

189. Nishimoto, M.; Fukushima, A.; Okuda, A.; Muramatsu, M. The gene for the embryonic stem cell coactivator UTF1 carries a regulatory element which selectively interacts with a complex composed of Oct-3/4 and Sox-2. Mol. Cell. Biol. 1999, 19, 5453-5465.

190. Jia, J.; Zheng, X.; Hu, G.; Cui, K.; Zhang, J.; Zhang, A.; Jiang, H.; Lu, B.; Yates, J., III; Liu, C.; et al. Regulation of pluripotency and self-renewal of ESCs through epigenetic-threshold modulation and mRNA pruning. Cell 2012, 151, 576-589.

(C) 2013 by the authors; licensee MDPI, Basel, Switzerland. This article is an open access article distributed under the terms and conditions of the Creative Commons Attribution license (http://creativecommons.org/licenses/by/3.0/). 